\title{
Portfolio Choice with Capital Gain Taxation and the Limited Use of Losses *
}

\author{
Paul Ehling ${ }^{\dagger}$ \\ BI Norwegian School of Management \\ Michael Gallmeyer ${ }^{\ddagger}$ \\ Sanjay Srivastava ${ }^{\S}$ \\ Mays Business School \\ Texas A\&M University \\ Stathis Tompaidis $\$$ \\ McCombs School of Business \\ University of Texas at Austin
}

November 18, 2007

${ }^{*}$ We would like to thank Victor DeMiguel, Lorenzo Garlappi, Spencer Martin, Jeffery Pontiff, Alan White, and seminar participants at the 2007 Bank of Canada/University of Toronto Workshop on Portfolio Management for useful discussions. A preliminary version of this paper was presented at the 2004 Annual Informs Meeting and preliminary results from this work were presented at the 2003 EIASM Workshop on Dynamic Strategies in Asset Allocation and Risk Management. Paul Ehling acknowledges financial support (små driftsmidler) from the Research Council of Norway.

${ }^{\dagger}$ paul.ehling@bi.no

$\ddagger_{\ddagger}^{\ddagger}$ mgallmeyer@mays.tamu.edu.

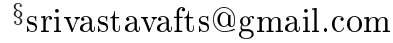

『Stathis.Tompaidis@mccombs.utexas.edu 


\section{Abstract \\ Portfolio Choice with Capital Gain Taxation and the Limited Use of Losses}

We study the consumption-portfolio problem with realized capital gain taxation. The distinguishing feature of our analysis is that we impose on the model an important element of the tax code that has received little attention in the academic literature: the limited use of capital losses. Existing capital gain tax portfolio choice work assumes the full use of capital losses (FUL). We show that this common assumption leads to counterfactual welfare results. Due to the tax rebates generated from tax loss selling, an untaxed investor would actually prefer to pay a capital gain tax. Instead, when only the limited use of capital losses (LUL) is allowed for, which is consistent with the U.S. tax code, an investor's optimal equity-to-wealth ratio is shown to be strongly non-monotonic in the portfolio's tax basis. For a tax basis significantly below the current stock price, LUL investors with no unrealized capital losses trade equity similar to FUL investors as the probability of tax loss selling in the future is small. For a tax basis close to the current stock price, LUL investors hold significantly less equity relative to FUL investors and untaxed investors. When LUL investors have large unused capital losses or a tax basis significantly above the current stock price, they trade as if they are not taxed on capital gains because they can use accumulated capital losses to offset any future taxes. This difference in trading strategies and the usage of capital losses leads to lower lifetime wealth and equity holdings for LUL investors relative to FUL investors and untaxed investors. These wealth and equity holding reductions are small under parameters from the current U.S. tax code, but are larger for capital gain tax rates consistent with past U.S. tax codes as well as tax codes in several foreign countries.

Keywords: portfolio choice, capital gain taxation, limited use of capital losses

\section{JEL Classification: G11, H20}




\section{Introduction}

Capital gain taxation has long been considered an important friction when investors make asset allocation and consumption decisions. However, integrating capital gain taxation into a portfolio choice setting is notoriously difficult. First, capital gain taxes are realization-based, or assessed only when a trading position is closed. The portfolio choice problem faced is essentially one with a statedependent transaction cost. Here the transaction cost is driven by current security prices and the tax basis of the trading position which usually is a complex function of past trading decisions. Second, in most countries, the portion of the tax code involving capital gain taxation is full of a myriad of details such as the treatment of long-term versus short-term capital gains, the computation of the tax basis, the taxation of different risky securities especially derivatives, and how capital gain taxes are computed at an investor's death.

Given these complexities, academic work studying portfolio choice with capital gain taxation typically adopts the most significant features of the tax code and assumes the other unmodelled features are of secondary importance. One feature of the tax code that has received little attention in the academic literature is that the use of capital losses is typically limited. ${ }^{1}$ In most tax codes, capital losses can only be used to offset current or future realized capital gains. Instead, it is commonly assumed that the use of capital losses is not restricted. If capital losses are larger than capital gains in a period, then the investor receives a tax rebate check from the taxing authority. The goal of this paper is to explore how the limited use of capital losses influences an investor's consumption-portfolio decision.

Specifically, we investigate the role of realized capital gain taxation with the limited use of capital losses on an investor's consumption-portfolio problem. For tractability, we assume an investor can trade in a single risky stock and a riskless money market. Essential to our analysis is that investors cannot perfectly offset all capital gain taxes as in the seminal work of Constantinides (1983). Indeed, based on provisions in tax codes such as the 1997 Tax Reform Act in the U.S. that ruled out "shorting the box" transactions ${ }^{2}$ as well as recent empirical evidence summarized in Poterba (2001), investors

\footnotetext{
${ }^{1}$ Our work is motivated by Gallmeyer and Srivastava (2003) who study no arbitrage restrictions on price systems in the presence of no wash sales and the limited use of capital losses. To our knowledge, this was the first work that explored the limited use of capital losses in capital gain tax problems.

${ }^{2}$ A "shorting the box" transaction involves realizing a capital gain with no tax consequences. This is achieved by taking an offsetting short position in the security that the investor would like to sell. Before the 1997 Tax Reform Act, such a trade was not viewed as a sale of the security and not subject to capital gain taxation.
} 
do realize capital gains and hence pay capital gain taxes. To be able to easily compare our analysis with past work, we modify the setting of Dammon et al. (2001b) to accommodate the limited use of capital losses. In this setting, the investor trades the stock and the money market to finance lifetime consumption. To rule out "shorting the box" trades, the investor is precluded from short-selling.

From our numerical analysis of the investor's consumption-portfolio problem, we find that imposing the limited use of capital losses leads to an optimal equity-to-wealth ratio that is strongly non-monotonic in the portfolio's tax basis. This is in contrast to imposing the full use of capital losses assumption where the equity-to-wealth ratio is monotonic in the portfolio's tax basis. This difference is driven by the inability to generate tax rebates under the limited capital loss assumption when the portfolio's tax basis is close to the current stock price. In this region, equity can be much less desirable to hold under the limited capital loss assumption as compared to the full capital loss assumption and the untaxed case.

When the portfolio's tax basis is much lower than the current stock price, the optimal equityto-wealth ratio behaves similarly across the full and limited use of capital losses assumption. In this region, the portfolio has a large embedded gain implying that an investor under the full capital loss assumption will not be receiving any tax rebates in the near future. Any equity trading will most likely result in positive capital gain taxes being paid.

When the portfolio's tax basis is higher than the current stock price, the optimal equity-to-wealth ratio under the limited use of capital losses converges to the optimal equity-to-wealth ratio of an investor who does not pay capital gain taxes. Given the investor's portfolio has a large capital loss, the limited use of capital losses assumption allows the investor to use the loss today to cover future realized capital gains. If this loss is large enough, all future capital gains can be offset leading to the convergence to the no capital gain tax optimal equity-to-wealth ratio. In contrast, the capital loss generates a tax rebate that is immediately capitalized into the investor's budget constraint under the full use of capital losses assumption. This tax rebate acts as a state-dependent dividend which makes holding equity less risky as it partially shields the investor from a drop in the equity price.

From these differences in optimal trading strategies across the full use and limited use of losses assumption, total equity exposure over the investor's lifetime tends to be lower under the limited use of losses. From an investor welfare perspective, we also document the cost of imposing each form of capital gain taxation on an untaxed investor. The tax rebate generated under the full use 
of capital losses generates a counterfactual result — an untaxed investor would actually prefer to pay capital gain taxes if the full use of losses is allowed. Such behavior is not exhibited if a capital gain tax is imposed with a limited use of losses. Under this form of capital gain taxation, no tax rebates are generated leading to the untaxed investor never preferring such a taxation scheme.

As mentioned earlier, the novelty of our work is in analyzing capital gain taxation with the limited use of losses. Several other papers have examined portfolio choice with capital gain taxation when the use of capital losses is not restricted. When "shorting the box" trades are allowed, Constantinides (1983) shows that an investor can optimally defer all gains and immediately realize all losses without influencing his portfolio decision. Central to Constantinides' analysis is the valuation of the cash stream created from tax-loss selling, commonly called the tax-loss option. When short-selling is prohibited, Dybvig and Koo (1996) provide a numerical study of after-tax portfolio choice. Due to computational issues, they study the problem for a limited number of time periods. Later work, based on Dammon et al. (2001b), assumes the tax basis follows the weighted-average of past purchase prices as in this paper. By doing so, after-tax portfolio choice can be studied by numerical dynamic programming for longer horizons. This work includes studies with multiple stocks (Dammon et al. (2001a); Garlappi et al. (2001); Gallmeyer et al. (2006)) and studies that explore investing simultaneously in taxable and tax-deferred accounts (Dammon et al. (2004); Huang (2001)). Using numerical nonlinear programming techniques, DeMiguel and Uppal (2005) study the utility cost of using the weighted-average of past purchase prices as a tax basis as compared to the exact share identification rule. For exact solutions to capital gain tax portfolio problems under restrictive conditions, see Cadenillas and Pliska (1999), Jouini et al. (2000), and Hur (2001). Again, all of this previous work assumes the use of capital losses is unrestricted.

One paper that does study the limited use of capital losses is concurrent work by Marekwica (2007), which we became aware of after preparing this manuscript. His work only studies conditional portfolio policies under the limited use of capital losses in a setting similar to our own. In contrast to his work, we stress the conditional differences between the full and limited use of capital losses as well as differences related to an untaxed investor. More importantly, we provide an analysis of the properties of lifetime portfolios and show that differences between the full and limited use of capital losses are less extreme than the conditional portfolio results suggest. Additionally, we provide a welfare analysis demonstrating that the full use of capital losses assumption leads to the 
counterfactual result that an untaxed investor would actually prefer to pay capital gain taxes under a full use of losses regime. The same is not true for the limited use of capital losses.

The paper is organized as follows. Section 2 describes the portfolio problem. Section 3 provides a simplified example that highlights the intuition behind the role of the limited use of capital losses. Our numerical analysis of optimal portfolios at a point in time is presented in Section 4. Section 5 reports lifetime properties of the optimal portfolios, while Section 6 analyzes the economic costs of capital gain taxation under both the full use of losses and the limited use of losses. Section 7

concludes. Appendix A gives a formal mathematical definition of the problem studied. Appendix B discusses the numerical procedure employed.

\section{The Consumption-Portfolio Problem}

The investor chooses an optimal consumption and investment policy in the presence of realized capital gain taxation at trading dates $t=0, \ldots, T$. The framework is an extension of the single risky asset model of Dammon et al. (2001b) where we modify capital gain taxation to accommodate for the limited use of capital losses. Our assumptions concerning the exogenous price system, taxation, and the investor's portfolio problem are outlined below. The notation and model structure are based from the setting in Gallmeyer et al. (2006). A full description of our partial equilibrium setting is given in Appendix A.

\subsection{Security Market}

The set of financial assets available to the investor consists of a riskless money market and a single dividend-paying stock. The money market pays a continuously-compounded pre-tax rate of return $r$. The stock pays a dividend with a constant dividend yield. The evolution of the ex-dividend stock price evolves as a binomial process.

\subsection{Taxation}

Interest income is taxed as ordinary income on the date that it is paid at the rate $\tau_{I}$. Dividends are also taxed on the date that they are paid, but at the rate $\tau_{D}$ to accommodate for differences in taxation between interest and dividend income. 
Our analysis centers around a feature of the tax code that has not received much attention in the academic literature, namely that most capital gain tax codes restrict how realized capital losses are used. The most common assumption used in the portfolio choice literature is that there are no restrictions on the use of capital losses. We refer to this case as the full use of capital losses (FUL) case.

Definition 1 (Full Use of Capital Losses (FUL) Case). An investor with the full use of capital losses faces no restrictions on their use. When realized capital losses are larger than realized capital gains in a period, the remaining capital losses generate a tax rebate that can be immediately invested.

Note that Definition 1 is the common assumption made in the portfolio choice literature with capital gain taxes (Constantinides (1983); Dammon et al. (2001b, 2004, 2001a); Garlappi et al. (2001); Hur (2001); Gallmeyer et al. (2006); DeMiguel and Uppal (2005)). In particular, it is always optimal for an investor to immediately realize a capital loss to capture the resulting tax rebate.

Given most capital gain tax codes restrict the use of capital losses, our alternative form of realized capital gain taxation is referred to as the limited use of capital losses (LUL) case.

Definition 2 (Limited Use of Capital Losses (LUL) Case). The use of capital losses is limited when realized capital losses can only be used to offset current realized capital gains when calculating capital gain taxes. Unused capital losses can be carried forward indefinitely to future trading dates.

Under the LUL case, we assume that the investor immediately realizes all capital losses even if they are not used. The no-arbitrage analysis in Gallmeyer and Srivastava (2003) shows that an investor is indifferent between realizing an unused capital loss or carrying it forward.

For tractability, our definition of the limited use of capital losses does not include the ability to use capital losses to offset current taxable income. In the U.S. tax code, individual investors can only offset up to $\$ 3,000$ of taxable income per year with realized capital losses. Additionally, our analysis does not distinguish between differential taxation of long and short-term capital gains since our investors trade at an annual frequency. For such an analysis, see Dammon and Spatt (1996).

Under both the FUL and the LUL cases, realized capital gains and losses are subject to a constant capital gain tax rate of $\tau_{C}$. When an investor reduces his outstanding stock position by selling, he incurs realized capital gains or losses subject to taxation. The tax basis used for computing these 
realized capital gains or losses is calculated as a weighted-average purchase price. ${ }^{3}$ In the FUL case, realized capital losses are treated as tax rebates, or negative taxes, for the investor. Hence, they lead to an increase in financial wealth when the loss is realized. In the LUL case, realized capital losses can only be used to offset current or future capital gains.

When an investor dies, capital gain taxes are forgiven and the tax basis of the stock resets to the current market price. This is consistent with the reset provision in the U.S. tax code. Dividend and interest taxes are still paid at the time of death. We also consider the case when capital gain taxes are not forgiven which is consistent with the Canadian tax code. While the investor can "wash sell" to immediately realize capital losses, he is precluded from shorting the stock which eliminates any ability to engage in a "shorting the box" transaction to avoid paying capital gain taxes. An imperfect form of "shorting the box" that involves trading in highly correlated, but different assets, is quantitatively studied in Gallmeyer et al. (2006).

\subsection{Investor Problem}

To finance consumption, the investor trades in the money market and the stock. Given an initial equity endowment, a consumption and security trading policy is an admissible trading strategy if it is self-financing, involves no short selling of the stock, and leads to nonnegative wealth over the investor's lifetime. The investor lives at most $T$ periods and faces a positive probability of death each period. The probability that an investor lives up to period $t<T$ is given by a survival function, calibrated to the 1990 U.S. Life Table, compiled by the National Center for Health Statistics where we assume period $t=0$ corresponds to age 20 and period $T=80$ corresponds to age 100 . At period $T=80$, the investor exits the economy with certainty.

The investor's objective is to maximize his discounted expected utility of real lifetime consumption and a time of death bequest motive by choosing an admissible consumption-trading strategy given an initial endowment. For tractability and ease of comparison with no tax portfolio problems,

\footnotetext{
${ }^{3}$ The U.S. tax code allows for a choice between the weighted-average price rule and the exact identification of the shares to be sold, while the Canadian tax code uses the weighted-average price rule. While choosing to sell the shares with the smallest embedded gains using the exact identification rule is clearly most beneficial to the investor, solving for the optimal investment strategy becomes numerically intractable for a large number of trading periods given the dimension of the state variable increases with time (Dybvig and Koo, 1996; Hur, 2001; DeMiguel and Uppal, 2005). Furthermore, for parameterizations similar to those in this paper, DeMiguel and Uppal numerically show that the certainty-equivalent wealth loss using the weighted-average price basis rule as compared to the exact identification rule is small.
} 
the utility function for consumption and wealth is of the constant relative risk aversion form with a coefficient of relative risk aversion of $\gamma$. Using the principle of dynamic programming, the Bellman equation for the investor's optimization problem, derived in Appendix A, can be solved numerically by backward induction starting at time $T$. Details of the computational complexity of this problem are outlined in Appendix B.

\subsection{Scenarios Considered}

To understand how the LUL case influences optimal portfolio choice relative to the FUL case, we focus on several scenarios where an investor faces different risk-return trade offs between the stock and the money market as well as different tax trading costs. Relative to the LUL and FUL assumptions, one benchmark we refer to is the case when the investor faces no capital gain taxation, abbreviated NCGT. In this benchmark, the investor still pays dividend and interest taxes. Given the investment opportunity set is constant and the investor has CRRA preferences in this benchmark, the optimal trading strategy is to hold a constant fraction of wealth in the stock at all times. Second, we also employ the FUL case as a benchmark to compare with the LUL case since the FUL assumption is commonly used in the academic literature.

In all our parameterizations, the investor begins investing at age 20 and can live to a maximum of 100 years. Hence, the maximum horizon for an investor is $T=80$. The inflation rate is assumed to be $i=3.5 \%$. The investor's constant relative risk averse preferences are calibrated with a time discount parameter $\beta=0.96$. The bequest motive is calibrated such that the investor plans to provide a perpetual real income stream to his heirs.

Our base case choice of parameters, referred to throughout as the "Base Case," views the stock as an index fund with price dynamics consistent with a large-capitalization U.S. stock fund. We assume the expected return due to capital gains is $\mu=7 \%$, the dividend yield is $\delta=2 \%$, and the volatility is $\sigma=20 \%$. The money market's return $r$ equals $6 \%$. The investor rebalances his portfolio once a year. The investor enters the economy at age 20 and exits no later than age 100. This choice of price system parameters is roughly comparable to those used in Dammon et al. (2001b) and Gallmeyer et al. (2006). The tax rates used are set to roughly match those faced by a wealthy investor under the current U.S. tax code. We assume that interest is taxed at the investor's marginal income rate $\tau_{I}=35 \%$. Dividends are taxed at $\tau_{D}=15 \%$. The capital gain tax rate is set 
to the long-term rate $\tau_{C}=15 \% .{ }^{4}$ To be consistent with the U.S. tax code, capital gain taxes are forgiven at the investor's death. The relative risk aversion coefficient is assumed to be $\gamma=3$.

We also consider several variations of the Base Case parameters. Most of these variations are meant to increase the value of the tax-loss selling option under the FUL case to capture an increased importance of tax-loss selling. An immediate way to increase the value of the FUL tax-loss selling option is just to increase the capital gain tax rate. In the "Capital Gain Tax 30\% Case", the capital gain tax rate is increased to $\tau_{C}=30 \%$, roughly equal to the $28 \%$ rate imposed after the U.S. 1986 Tax Reform Act. This rate also provides a setting that is roughly consistent with the long-term capital gain tax rate paid in many foreign countries. For example, the capital gain tax rates in Finland, France, Sweden and Norway are currently 28\%, 26\%, 30\%, and 28\% respectively. In 2009, Germany's individual capital gain tax rate will rise to $25 \%$ from $0 \%$. To capture extreme values of the tax loss selling option, the "Capital Gain Tax 50\% Case" assumes $\tau_{C}=50 \%$. ${ }^{5}$ To capture a case where stock holdings increase for the NCGT investor and hence the dollar value of tax-loss selling increases for the FUL investor, the "Lower Risk Aversion Case" assumes that the relative risk aversion of the investor falls to $\gamma=2$. Finally, given tax forgiveness at death is primarily a feature of only the U.S. tax code, the "No Tax Forgiveness at Death Case" assumes capital gain taxes are assessed when the investor dies, a feature consistent with the Canadian tax code for example.

\section{A Two Date Example}

Before numerically studying the consumption-portfolio problem outlined in Section 2, we first analyze a two trading date example to highlight the role the limited use of capital losses plays in determining an investor's optimal trading strategy. Given the portfolio problem only lasts for two periods, this example conveniently allows us to follow the optimal trading path of the investor over time.

\footnotetext{
${ }^{4}$ The U.S. Tax Relief and Reform Act of 2003 changed several features of the tax code with respect to investments. In particular, the long-term capital gain tax rate dropped from $\tau_{C}=20 \%$ to $\tau_{C}=15 \%$ for most individuals. Dividend taxation switched from being linked to the investor's marginal income tax rate to a flat rate of $\tau_{D}=15 \%$. The 2006 Tax Reconcilation Act extended these rates to be effective until 2010. From 2011 and on, these rates will generally revert to the rates effective before 2003 unless another tax law change is made.

${ }^{5}$ We also considered a setting with a higher stock volatility where we adjusted the pre-tax Sharpe ratio of the stock so that the NCGT investor holds the same equity position as in the Base Case. This increase in volatility increases the value of the tax-loss selling option for the FUL investor. The results are similar to the case of increasing the capital gain tax rate and are available from the authors.
} 
In this example which is a simplified version of the model in Section 2, the investor lives with probability one until $T=2$ and maximizes the expected utility of final period wealth with CRRA preferences with a coefficient of relative risk aversion equal to 3 . The investor trades in a nondividend paying stock and a riskless money market. The stock's price evolves as a binomial process with an initial price of one. Hence, the investor will make a portfolio choice decision at $t=0$ and $t=1$ conditional on the stock going up or down in price. Over the investor's lifetime, he pays taxes on the money market's interest payment as well as capital gain taxes on the stock. At time $T=2$, the portfolio is liquidated and the investor consumes the after-tax wealth. To purely isolate the difference between the FUL and LUL cases, no capital gain tax liabilities are forgiven at time $T=2$. Capital gain tax forgiveness at death is considered in the long-dated portfolio problem studied in Sections 4 through 6. The investor is initially endowed with one share of stock with a pre-existing tax basis that is allowed to vary to capture different tax trading costs. When the tax basis is initially set lower (higher) than the $t=0$ stock price, the investor has a capital gain (loss) in his endowed stock position.

Using the same notation as Section 2 and Appendix A, the parameters of the price system are $S_{0}(0)=S_{1}(0)=1, r=0.05, \mu=0.077$, and $\sigma=0.18$, where $S_{0}$ denotes the money market and $S_{1}$ is the stock price. From $\sigma=0.18$, the rate of appreciation (depreciation) of the stock over one time period is $1.20(1 / 1.20)$. The tax rates are $\tau_{I}=0.35$ and $\tau_{C}=0.3$. The range for the investor's endowed tax basis is $[0.69,1.44]$ which corresponds to the lowest and highest stock price achievable at time $t=2$. Choosing this range for the tax basis allows us to capture a broad range of potential scenarios for how taxes are paid.

We examine three different cases - a no capital gain tax case (NCGT), a full use of losses capital gain tax case (FUL), and a limited use of losses capital gain tax case (LUL). Figures 1-3 summarize the optimal portfolio choice, wealth, expected utility, and capital gains taxes for different basis-to-price ratios at $t=0$. Again, a basis-to-price ratio below one corresponds to the investor initially having a capital gain in his stock position; a basis-to-price ratio above one corresponds to the investor initially having a capital loss in his stock position. At a basis-to-price ratio equal to one, the investor can trade at $t=0$ with no capital gain tax implications.

Figure 1 reports the after-tax optimal stock position as shares (left panels) and as a fraction of wealth (right panels) across the three cases for time $t=0$ (top panels), time $t=1$ with a stock 
price rise (middle panels), and time $t=1$ with a stock price drop (bottom panels). Figure 2 reports the after-trade wealths at $t=0$ (top left panel), $t=1$ (middle left panels), and $t=2$ (right panels) as well as the time $t=0$ expected utility (bottom left panel) across the three cases. Finally, Figure 3 reports the capital gains taxes collected at time $t=0,1,2$ and is oriented the same as Figure 2. In each figure, the solid line corresponds to the LUL case, the dashed line corresponds to the FUL case, and the dashed-dotted line corresponds to the NCGT case.

The NCGT case provides a convenient benchmark to compare the two capital gain tax cases. Given the investor has no labor income, has CRRA preferences, and faces a constant opportunity set, he holds a constant fraction of his wealth in equity at all times. Specifically, from the dasheddotted lines in the right panels of Figure 1, the investor always holds approximately $51 \%$ of his wealth in the stock. To maintain this constant fraction, the investor trades shares of stock each period. From the left panels of the figure, the investor initially reduces his position from 1 share to 0.51 shares; the proceeds of selling 0.49 shares are invested in the money market. At $t=1$ when the stock price increases, the investor's fraction of wealth in equity rises above its optimal amount. The investor then reduces his equity position to 0.47 shares (middle left panel) and invests the sale proceeds in the money market. When the stock price decreases at $t=1$, the investor is underexposed to equity and buys shares by selling part of his money market investment leading to a position of 0.57 shares (bottom left panel).

With capital gain taxes, the investor can no longer costlessly trade as in the NCGT case leading to significant deviations from the no tax case. We first examine the FUL case (dashed lines in Figures 1-3) to examine how the full use of capital losses influences portfolio choice.

From Figure 1, the FUL case (dashed lines) leads to higher equity holdings from both the share and fraction of wealth perspective relative to the NCGT case at $t=0$ (top panels). When the basis-to-price ratio of the endowment is less than one initially, this increase in equity holdings is driven by the tax costs to trade as can be seen in the taxes paid at $t=0$ plot (top left panel of Figure 3). Given the investor is initially grossly undiversified since all his wealth is held in one share of stock, he sells stock to better balance the risk-return tradeoff of holding stock relative to the money market, but pays capital gain taxes to do so. At $t=1$ if the stock goes up (middle panels of Figure 1), the FUL investor again sells more shares to reduce his over-exposure to equity, but pays capital gain taxes to do so (middle left panel of Figure 3). At $t=1$ if the stock goes down (bottom 
panels of Figure 1), the FUL investor increases the number of shares of equity he holds leading to a higher fraction of wealth in stock as compared to the NCGT investor. Although he will pay capital gain taxes at $t=2$ if the stock goes up at $t=2$, he will start receiving tax rebates if the stock goes down at $t=2$ (bottom right panel of Figure 3 ). Overall at $t=0$, as the basis-to-price ratio moves closer to one, the tax trading costs are lower and the investor holds less equity, but still more as compared to the NCGT case.

When the basis-to-price ratio is greater than one initially, the trading strategy in the FUL case is influenced by the ability to tax-loss sell the embedded capital loss. Since the investor is unrestricted on how realized capital losses can be used, he receives a tax rebate from the taxing authority in the form of a negative capital gain tax that can be immediately invested. The tax rebate from tax loss selling can be interpreted as a state-dependent dividend being paid by the stock when the stock price drops. This distortion leads to the investor buying more stock the greater the capital loss as can be seen in the top left panel of Figure 1. Moreover, his fraction of wealth invested in the stock, as seen in the top right panel, is relatively constant. This additional stock investment is financed by the increase in wealth due to the tax rebate as can be seen in the upper left hand panels of Figures 2 and 3. Furthermore, this increase in wealth leads to larger equity positions at time $t=1$ relative to the NCGT case as can be seen in the two lower panels of Figure 1. Additionally, if the stock drops at $t=1$, the FUL investor once more collects a tax rebate by tax loss selling, again leading to an increase in wealth.

We now turn to the LUL case (solid lines in Figures 1-3) to understand how the limited use of capital losses drives portfolio choice. From Figure 1, optimal equity allocations are starkly non-monotonic as compared to the NCGT and FUL cases. This behavior is tightly linked to the restriction now placed on the use of capital losses under the LUL assumption.

When the embedded capital gain in the portfolio is initially large, the LUL case is identical to the FUL case because the investor will never tax-loss sell at any time. This corresponds to a basis-to-price ratio of 0.69 initially and is the leftmost point in all plots of Figures 1-3. Given the investor is initially endowed with an all equity position with a large embedded gain, all trades at $t=0$ and $t=1$ lead to positive or zero capital gain taxes in both the LUL and the FUL cases (see Figure 3). The equity position at time $t=0$ is larger than the NCGT case given the tax trading costs of reducing the equity position with the large embedded capital gain. 
As the basis-to-price ratio rises above 0.69 , the LUL and the FUL strategies diverge dramatically with the LUL equity position falling significantly for basis-to-price ratios around 1.0 at time $t=0$ as can be seen in the top panels of Figure 1. For example, when the basis-to-price ratio equals 1.0 implying no initial embedded gains, the LUL investor's stock position as a fraction of wealth is 0.33 , 0.31 , and 0.33 at $t=0, t=1$ stock up, and $t=1$ stock down, respectively. For the FUL investor, these portfolio weights are significantly higher at $0.52,0.54$, and 0.52 , respectively.

This reduction in equity holdings relative to the FUL case is driven by the reduction in value of tax-loss selling the stock. In the FUL case, capital losses acted as a payoff to cushion down stock market movements. With the LUL case, these realized capital losses can only be used to lower future capital gain taxes and possibly could go unused. The smallest equity holding for the LUL case at $t=0$ occurs when the basis-to-price ratio is slightly above 1.0. Here the initial loss in the investor's portfolio is realized and used to offset any future capital gains. By taking a reduced equity position at $t=0$, the investor is able to avoid paying any capital gain taxes in the future. In particular, if the stock goes up at $t=1$ and up again at $t=2$, the accumulated gains from holding stock over these two periods are covered by the original realized capital losses at $t=0$. Such behavior is evident in Figure 3 where under the LUL scenario, no capital gain taxes are paid in any state once the basis-to-price ratio is large enough.

As the basis-to-price ratio increases above 1.0, the LUL trading strategy converges to the NCGT trading strategy. Note that this is also equivalent to endowing the LUL investor with a large unused capital loss initially. This occurs if the capital loss in the investor's portfolio is large enough to offset all future capital gain taxes when the LUL investor trades the NCGT strategy. From Figure 1, this occurs when the initial basis-to-price ratio is slightly above 1.2. Note that the FUL stock trading strategy always is higher than the NCGT strategy in this region. Here the FUL investor tax loss sells and uses the tax rebate to finance larger equity holdings. Ultimately, this leads to higher time $t=2$ wealths in all states and a higher expected utility relative to the LUL and NCGT cases as can be seen in the right panels and the bottom left panel of Figure 2.

Overall, this simple three date example highlights that the FUL and LUL cases can lead to starkly different trading strategies when the FUL investor engages in tax-toss selling. We now turn to a long-dated consumption-portfolio problem to understand how the FUL and the LUL trading strategies are quantitatively different. 


\section{The Conditional Structure of Optimal Portfolios}

We begin our numerical analysis of the long-dated portfolio problem outlined in Section 2 by characterizing the structure of optimal portfolios under the FUL and the LUL cases at a particular time and state. This analysis shows conditionally how the two tax cases differ as a function of the state variables. It however does not provide a full picture of the optimal strategies over the investor's lifetime as these strategies are just snapshots at a particular state and time. An analysis of lifetime portfolio holdings is undertaken in Section 5.

\subsection{The Base Case}

Figure 4 presents optimal stock-to-wealth ratios conditional on the beginning period stock-to-wealth and basis-to-price ratios for the FUL and the LUL cases. The LUL case is assumed to have a zero carry-over loss. The parameters used are the Base Case parameters. Additionally, Table 1 provides the same information numerically as Figure 4 for a subset of the beginning period stock-to-wealth and basis-to-price ratios. The left (middle) panel is for the FUL (LUL) case. The right panel computes the percentage increase of the stock-to-wealth ratio for the FUL case relative to the LUL case. We do not report conditional trading strategies in the LUL case for nonzero carry over losses entering the trading period. Based on our simulation analysis in the next section, nonzero carry over losses mainly occur with stock positions with basis-to-price ratios close to one along the investor's optimal path. Hence, this situation is well-captured by just examining trading strategies with basis-

to-price ratios bigger than one entering the period. For the NCGT benchmark, the optimal portfolio choice is a stock-to-wealth ratio of 0.228 at all times for these parameters.

The left panels of Figure 4 document optimal portfolio choice for the FUL case at ages 20 (top panel) and 80 (bottom panel). Such trading strategies are well-documented in Dammon et al. (2001b) for example. Here we briefly discuss their main features, especially those pertinent in comparing with the LUL case. The investor's optimal equity position is a function of the beginning period allocation and the basis-to-price ratio. Tax trading costs play a large role in the investor's portfolio choice decision. When the marginal tax costs of trading are high due to a large embedded capital gain, the investor optimally chooses to hold more equity. For example at age 20 with a beginning period stock-to-wealth ratio of 0.40 , the investor trades to an equity position of 0.292 
when the basis-to-price ratio is 0.5 and an equity position of 0.227 when the basis-to-price ratio is 1.0. Given the forgiveness of capital gain taxes at death, the marginal tax cost of trading effectively increases with age. At age 80 and a beginning period stock-to-wealth ratio of 0.40 , the optimal equity position increases to 0.347 when the basis-to-price ratio is 0.5 . Overall, optimal equity allocations under the FUL case can rise significantly above the NCGT benchmark of 0.228. Even when there are no capital gains embedded in the portfolio, FUL equity allocations at age 20 are approximately equal to the NCGT allocation and higher than the NCGT allocation at age 80.

The right panels of Figure 4 document optimal portfolio choice at ages 20 and 80 for the LUL case. As compared to the FUL case, the LUL equity strategy is non-monotonic along the basis-toprice dimension as in the example from Section 3. With the restriction on the use of capital losses from the LUL case, equity allocations when the basis-to-price ratio is around 1.0 are most strongly influenced. For example at age 20 and a basis-to-price ratio of 1.0, the LUL equity allocation is 0.172 while the FUL equity allocation is 0.227 . Relative to the LUL case, this FUL allocation is $32.0 \%$ higher as can be seen in the right top panel of Table 1 . At age 80, the difference between the two trading strategies is even more acute with the FUL investor's equity position $35.1 \%$ higher than the LUL investor's equity position at a basis-to-price ratio equal to one.

This reduction in equity is driven by the restrictions on the use of capital losses placed on the LUL investor. At a basis-to-price ratio around one, an FUL investor has the potential to tax loss sell next period and receive a tax rebate. The LUL investor however will only potentially receive a capital loss to carry forward to the next trading period.

Equally interesting is how the two different assumptions on capital losses lead to different equity positions when the basis-to-price ration is equal to one relative to the NCGT case. At age 20, the FUL investor holds virtually the same fraction of wealth in equity as the NCGT investor. Here, even though the FUL investor pays taxes when the stock appreciates in value and he realizes gains, his downside risk of holding stock is reduced relative to the NCGT case through the tax rebates received when the stock price falls.

In contrast, the LUL investor's after-tax payoff on the stock is not higher than the NCGT case when the stock price falls. Given realized capital losses can only be used to offset future realized capital gains, the after-tax payoff of the stock is always worse for the LUL investor relative to the NCGT investor's stock payoff. The two will only be the same if the LUL investor accumulates a 
lifetime worth of capital losses to use to offset all future capital gain taxes.

Like the Section 3 example, the LUL equity strategy converges to the FUL equity strategy when the investor is over invested in equity with a large capital gain. In this situation, the probability that the FUL investor engaging in any tax loss selling is greatly reduced given the large locked-in capital gain in the portfolio. Hence, the two strategies converge as can be seen when the basis-to-price ratio is low and the beginning period equity allocation is high. For example, the FUL and LUL equity positions both equal 0.347 at an initial stock allocation of 0.45 and a basis-to-price ratio of 0.5 at age 80 .

The LUL strategy also converges to the NCGT strategy when the investor enters the period with a large capital loss. From Table 1 at a basis-to-price ratio of 1.1, the LUL equity allocation converges to the NCGT equity allocation of 0.228 as the beginning period stock-to-wealth ratio increases to 0.45 . Here the capital loss in the portfolio is large enough that the LUL investor can trade the same strategy as the NCGT investor and offset all future capital gain taxes. Note that this convergence of the trading strategy to the NCGT case would also occur when the LUL investor's carry over loss is large.

Summarizing, under the Base Case parameters, the LUL optimal equity allocation is strongly non-monotonic relative to the FUL optimal equity allocation along the basis-to-price dimension. When tax costs of trading are low, the LUL allocation falls significantly relative to both the FUL and the NCGT allocations. When the LUL investor has a position with a large embedded gain, he is locked into his position like the FUL investor. When large capital losses are accumulated by the LUL investor, his trading strategy resembles the NCGT investor's strategy.

\subsection{Comparative Statics}

Tables 2 through 5 report optimal equity allocations for several variations of the Base Case parameters. Tables 2 and 3 explore the effect of increasing the capital gain tax to $30 \%$ and $50 \%$ on the FUL and the LUL optimal equity strategies. Given changing the capital gain tax rate influences both the expected return and the volatility of the stock, it is not immediately apparent how portfolio allocations will be influenced. However, from Constantinides (1983), we know the value of the tax loss selling option increases as the capital gain tax rate increases. The $30 \%$ rate is roughly consistent with the old $28 \%$ capital gain tax rate imposed in the U.S. after the 1986 Tax Reform Act as well 
as the tax rate in several foreign countries. The $50 \%$ rate is simply meant to capture an extreme level of capital gain taxation. When the basis-to-price ratio is 1.0, the optimal equity allocations at ages 20 and 80 drop under the LUL case when the capital gain tax rate increases as compared to the Base Case. With the increase in the tax rate, the benefit of holding equity is reduced leading to lower allocations. Again, the LUL investor's after-tax opportunity set worsens with the higher tax rate.

The same effect does not occur for the FUL case however. When the basis-to-price ratio is 1.0, the FUL investor might actually hold more equity as the capital gain tax rate increases. In the Capital Gain Tax 30\% Case for example, the FUL investor's optimal stock-to-wealth ratio rises to 0.293 as compared to 0.235 in the Base Case at age 80. The Capital Gain Tax $50 \%$ Case leads to even larger increases in equity holdings. At age 80, the FUL investor's stock-to-wealth ratio rises to 0.406 when the basis-to-price ratio is 1.0. Given the investor's horizon has shortened, he is willing to hold a larger equity position to realize tax loss selling options.

The risk aversion of the investor is decreased to $\gamma=2$ in Table 4 to capture a scenario where equity is a more important component of the investor's portfolio. In this case, the NCGT equity-towealth allocation is 0.343 as compared to 0.228 under the Base Case parameters. Decreasing the risk aversion leads to largely the same feature as in the Base Case - the LUL optimal equity allocation is again strongly non-monotonic along the basis-to-price dimension, but at higher allocations given the drop in the investor's risk aversion.

Given the U.S. tax code has the unique feature of capital gain taxation forgiveness at death, Table 5 reports the optimal equity allocations when capital gain taxation is not forgiven at death as in, for example, the Canadian tax code. With no tax forgiveness, optimal equity allocations under the FUL and LUL cases no longer increase strongly with age as can be seen by comparing Panel A (age 20) with Panel B (age 80). Importantly, the LUL equity allocation still retains its non-monotonic pattern as in the base case.

\section{The Lifetime Structure of Optimal Portfolios}

While examining optimal portfolio choice at a particular time and state is useful in understanding the conditional differences in the FUL and the LUL trading strategies, it provides limited information 
about any differences in portfolio composition over an investor's lifetime. Indeed, these conditional snapshots are exactly that - they contain limited information about how an investor's portfolio optimally evolves through time. For example, it is very unlikely along an optimal trading path that an investor will simultaneously have a large carry over loss and a large equity position with a low tax basis. Also, the conditional snapshots do not easily summarize the increase in wealth from tax rebates collected by the FUL investor.

To gain insights about portfolio choice along the optimal strategy taken over an investor's lifetime, we perform Monte Carlo simulations starting with no embedded stock gains at age 20 and an initial wealth of $\$ 100$ to track the evolution of the investor's optimal portfolio at ages 40,60 , and 80 conditional on the investor's survival. These results are reported in Tables 6-8 for the Base Case parameters and the variations on the Base Case parameters. All simulations are over 50,000 paths and computed for the FUL and LUL investors.

Tables 6 and 7 report characteristics of the FUL and LUL portfolio choice problesm at ages 40 (Panel A), 60 (Panel B), and 80 (Panel C) for the Base Case and Capital Gain Tax 30\% Case. For brevity, Table 8 only reports age 80 simulation results for the Capital Gain Tax $50 \%$ Case (Panel A), the Lower Risk Aversion Case (Panel B), and the No Tax Forgiveness at Death Case (Panel C). For each quantity reported, the percentiles of the distribution, the mean, and the standard deviation are reported. The column labeled "Wealth" gives the investor's current financial wealth expressed in dollars. The columns labeled "Stock-to-Wealth Ratio" and "Basis-to-Price Ratio" present the characteristics of the optimal equity position. The "Cumulative Capital Gain Tax-to-Wealth Ratio" column presents the cumulative taxes paid from age 20 to the current age divided by the wealth at the current age. Finally, the column "LUL Carry Over Loss-to-Wealth Ratio" presents the carry over loss variable at the current age.

\subsection{The Base Case}

The Base Case simulations are presented in Table 6. The ability to tax loss sell in the FUL case leads to higher wealths on average relative to the LUL case at all ages. At ages 60 and 80, the FUL wealth distribution is weakly higher at all deciles relative to the LUL wealth distribution. This increase in the FUL wealth distribution is driven by two effects - higher equity holdings and tax rebates collected through tax loss selling. From the stock-to-wealth ratio column, the FUL equity 
holdings dominate the LUL equity holdings at all ages until the 80th percentile leading to on average higher equity holdings in the FUL case. This difference in equity holdings is driven by the original divergence in equity holdings in the FUL and LUL cases when the basis-to-price ratio is around 1.0.

Tax loss selling also plays a role in the higher FUL wealth distribution. Note that the cumulative capital gain tax-to-wealth ratios are negative for the lower deciles at all ages for the FUL case. This is capturing the tax rebates being collected when the FUL investor tax loss sells.

The Base Case simulations also highlight that LUL investor's carry over loss is also typically quite small. At age 40, the average carry over loss is $0.5 \%$ of wealth. Also, the distribution is heavily skewed toward zero as can be seen in the percentiles. Hence, the investor rarely has a significant carry over loss in his portfolio over his lifetime.

Overall, the Base Case simulations highlight that under both the FUL and LUL cases, the investors get capital gains locked in quickly and actually pay little capital gain taxes over their lifetimes. Even though the capital gain tax is $15 \%$, effectively it is significantly smaller.

\subsection{Comparative Statics}

Table 7 presents the same simulation results for the Capital Gain Tax 30\% Case. Given the capital gain tax rate is now higher, the effects seen in the Base Case now grow stronger. For example, average equity holdings across the FUL and LUL cases grow wider - at age 80 the FUL investor's equity

position is $14.6 \%=\frac{0.392-0.342}{0.342}$ higher. Also, the difference between the wealth distributions increases due to the larger spread in equity holdings as well as the additional tax loss selling performed by the FUL investor. In particular, average capital gain taxes under the FUL case are negative at age 40 and approximately zero at ages 60 and 80 .

Table 8 summarizes the age 80 simulations for the other cases. The Capital Gain Tax $50 \%$ Case (Panel A) shows even stronger effects - in particular average collected capital gain taxes are now negative at age 80 for the FUL investor. Panel B of Table 8 presents the same simulations for the Lower Risk Aversion Case. Given the increase in equity holdings, the difference between the FUL and LUL wealth distributions is amplified relative to the Base Case parameters. The size of tax loss selling is also larger in the FUL case now. At age 40 in the FUL case, cumulative capital gain taxes are actually negative on average. The No Tax Forgiveness at Death Case simulation given in Panel C highlights how tax forgiveness drives higher equity holdings later in life across both the FUL and 
the LUL cases. Note that the average equity holdings are much lower across both the FUL and the LUL cases relative to the Base Case. Given there is no tax forgiveness at death, the investor's marginal tax cost to trade is no longer a function of age as in the Base Case. The FUL and LUL wealth distributions still exhibit differences with the FUL distribution higher at all deciles for age 80.

\section{The Economic Costs of the FUL and the LUL Cases}

Our analysis of the conditional structure of optimal portfolios in Section 4 demonstrated that optimal portfolios across the FUL and LUL cases can greatly differ when the basis-to-price ratio is around one. The lifetime portfolio analysis of Section 5 partially mitigates the differences though — over an investor's life, he typically holds a stock position with a significant embedded gain regardless of the FUL or LUL assumption. However, optimal wealth distributions and taxes collected do differ. We now attempt to quantify the economic significance of the difference between the FUL and the LUL cases in Tables 9 and 10.

Each table reports the wealth change of an age 20 NCGT investor due to imposing a capital gain tax. We present results conditional on his endowed equity position and basis-to-price ratio. Table 9 reports wealth changes under the Base Case (Panel A) and the Capital Gain Tax 30\% Case (Panel B). Table 10 reports wealth changes under the Capital Gain Tax 50\% Case (Panel A), the Lower Risk Aversion Case (Panel B), and the No Tax Forgiveness Case (Panel C). In each panel, the left table presents the FUL wealth change, the middle table presents the LUL wealth change, and the right table computes the difference in wealth changes (FUL-LUL).

The wealth change presented in the tables measures the change in the NCGT investor's wealth, expressed as a percentage, in order for the investor to be indifferent between switching to capital gain taxation with a particular portfolio or remaining untaxed on capital gains. If the wealth change is negative, it implies the investor is worse off when forced to pay capital gain taxes. A positive wealth change implies the investor is better off paying capital gain taxes as compared to be untaxed. Our measure of the cost of taxation is in contrast to most existing literature (Constantinides (1983); Dammon et al. (2001b); Garlappi et al. (2001)) as we do not measure tax costs relative to an accrual-based capital gain taxation system where all gains and losses are 
marked-to-market annually. Instead, our wealth change measure is meant to capture the change in an investor's welfare by imposing a capital gain taxation scheme. All results presented are from the perspective of an age 20 investor.

\subsection{The Base Case}

Under the FUL form of capital gain taxation, the wealth changes under the Base Case parameters (Panel A of Table 9) show a striking feature - an investor not currently taxed on capital gains would actually prefer to switch to paying capital gain taxes as long as his initial portfolio is free of embedded capital gains. From the FUL table in Panel A, the wealth change when the basis-to-price ratio is 1 is $0.1 \%$. The NCGT investor would actually be slightly better off paying capital gain taxes under the FUL scheme. The same is not true for the LUL taxation scheme. When the basis-to-price ratio is 1.0 , the wealth change due to switching to the LUL capital gain taxation scheme is $-1.2 \%$.

When the NCGT investor is offered to switch to a large equity position with a large embedded gain, the FUL and LUL wealth changes are still different with the LUL wealth change being lower. For example, at an initial stock position expressed as a fraction of wealth of 0.50 and a basis-toprice ratio of 0.5 , the difference between the FUL and LUL wealth changes is $0.6 \%$. This difference implies that in the future, the two optimal trading strategies will diverge with a positive probability with the FUL investor potentially engaging in tax loss selling.

The value of starting with a capital loss in the investor's portfolio is captured by a basis-to-price ratio above one. Here the difference between the FUL and LUL wealth changes is greatest since the FUL investor immediately tax loss sells capturing a tax rebate. When the NCGT investor starts with an initial stock position of 0.20 and a basis-to-price ratio of 1.2 , the difference between the FUL and LUL wealth changes is $1.7 \%$ of current wealth.

\subsection{Comparative Statics}

Increasing the capital gain tax rate amplifies the difference between the FUL and the LUL wealth changes as can be seen in Panel B of Table 9 and Panel A of Table 10. As the capital gain tax rate increases, the FUL wealth change at a basis-to-price ratio of 1.0 becomes even more positive: $1.2 \%$ when $\tau_{C}=30 \%$ and $3.8 \%$ when $\tau_{C}=50 \%$. In contrast, the LUL wealth ratio becomes even more negative: $-1.5 \%$ when $\tau_{C}=30 \%$ and $-1.6 \%$ when $\tau_{C}=50 \%$. The positive wealth ratios under the 
FUL case demonstrate the increased importance of the tax loss selling option in driving optimal portfolio decisions.

When the investor's risk aversion falls leading to larger equity positions, the wealth changes are amplified relative to the Base Case parameters. Panel B presents the same results for the Lower Risk Aversion Case. When the basis-to-price ratio is 1.0, the FUL wealth change is even more positive at $0.6 \%$, while the LUL wealth change is even more negative at $-1.4 \%$.

Tax forgiveness at death plays an important role in making the FUL wealth change positive as demonstrated by the No Tax Forgiveness at Death Case given in Panel C. In the FUL table of Panel $\mathrm{C}$, the wealth change is $-1.0 \%$ when the basis-to-price ratio is 1.0. By removing an investor's ability to shield capital gains from taxation at death, the wealth change becomes negative. The LUL wealth changes are still lower than the FUL wealth changes at all allocations and basis-toprice ratios. This implies that even under no tax forgiveness at death, tax loss selling still has an important role in mitigating the cost to the investor of the capital gain tax.

\section{Conclusion}

Given that integrating capital gain taxation into a portfolio choice setting can be difficult, it is common to adopt the most significant features of the tax code and assume any other features are of secondary importance. Our work focuses on one feature of the capital gain tax code that has received little attention in the academic literature - the limited use of capital losses. Rather than allowing capital losses to generate tax rebates if there are no realized capital gains to offset against, we require that capital losses can only be used to offset current or future realized capital gains.

Under this restriction on the use of capital losses, we study an investor's consumption-portfolio problem in the presence of capital gain taxation. In contrast to when the use of capital losses is unrestricted, we show that the optimal equity-to-wealth ratio is non-monotonic in the portfolio's tax basis. In particular, equity holdings can be significantly smaller under the limited use of losses when the tax basis is close to the current stock price. When examining the optimal portfolios over an investor's lifetime, the differences across the full and limited use of losses are partially mitigated as trading strategies under each setting tend to lead to larger equity positions with a small tax basis over time. We also document a counterfactual welfare result when the use of capital losses is 
unrestricted. If an investor faces capital gain taxation with the unrestricted use of capital losses, he actually prefers to pay capital gain taxes rather than being untaxed. This desire is generated from the stream of cash flows generated from the tax rebates.

For tractability, we have restricted our analysis to a single risky stock and a money market setting. A natural question to ask is how the limited use of capital losses influences equity trading decisions in the presence of multiple stocks. With more stocks, simultaneous capital gains and losses can occur in the portfolio. We are currently exploring the two stock case by extending the analysis in Gallmeyer et al. (2006). Such an analysis is complicated by the need to carry an additional state variable, the carry-over capital loss. 


\section{A Investor Consumption-Portfolio Problem with Capital Gain Taxes}

The mathematical description of the portfolio problem outlined in Section 2 is now presented. Our single risky stock model is an extension of the single-stock setting of Dammon et al. (2001b) and heavily follows the notation and setup of Gallmeyer et al. (2006) but for only one risky stock. The major difference in our work is that it accommodates for the limited use of capital losses.

\section{A.1 Security Market}

The economy is discrete-time with trading dates $t=0, \ldots, T$. Each period, the investor can trade in two assets: a riskless money market and a risky dividend-paying stock.

The riskless money market has a time $t$ price of $S_{0}(t)$ and pays a continuously compounded pre-tax interest rate $r$. The money market's price dynamics are given by

$$
S_{0}\left(t+\Delta_{t}\right)=S_{0}(t) \exp \left(r \Delta_{t}\right)
$$

where $\Delta_{t}$ is an arbitrary time interval. To match the trading interval of the investor in our economy, we assume that $\Delta_{t}=1$ with time units measured in years.

Stock market investment opportunities are represented by a single stock with a time $t$ exdividend price $S_{1}(t)$. The stock pays a pre-tax dividend of $\delta_{1} S_{1}(t)$ at time $t+\Delta_{t}$ where $\delta_{1}$ is the stock's dividend yield. The stock's pre-tax ex-dividend price follows a binomial process with price dynamics over the time interval $\Delta_{t}$ given by:

$$
S_{1}\left(t+\Delta_{t}\right)=S_{1}(t) \exp \left(\left(\mu-\frac{1}{2} \sigma^{2}\right) \Delta_{t}+\sigma \sqrt{\Delta_{t}} \tilde{z}\right)
$$

where $\tilde{z}$ is a binomial random variable taking the two values -1 and 1 with a probability distribution specified as $p(\tilde{z}=1)=p(\tilde{z}=-1)=\frac{1}{2}$. The quantity $\mu$ is the instantaneous capital gain expected growth rate and $\sigma$ is the instantaneous volatility of the stock.

\section{A.2 Investor's Problem}

Given a discrete-time economy with trading dates $t=0, \ldots, T$, an investor endowed with initial wealth in the assets chooses an optimal consumption and investment policy in the presence of realized capital gain taxation. The investor lives for at most $T$ periods and faces a positive probability of death each period. The probability that an investor lives up to period $t, 0<t<T$, is given by

the survival function $H(t)=\exp \left(-\sum_{n=0}^{t} \lambda_{n}\right)$ where $\lambda_{n}$ is the single-period hazard rate for period $n$ where we assume $\lambda_{n}>0, \forall n$, and $\lambda_{T}=\infty$. This implies $0 \leq H(t)<1, \forall 0 \leq t<T$. At $T$, the investor exits the economy, implying $H(T)=0$. We assume that the investor makes annual decisions starting at age 20 corresponding to $t=0$ with certain exit from the economy at age 100 implying $T=80$. The hazard rates $\lambda_{n}$ are calibrated to the 1990 U.S. Life Table compiled by the National Center for Health Statistics to compute the survival function $H(t)$ from ages $20(t=0)$ to 
$99(t=79)$.

An investor's trading strategy from time $t$ to $t+1$ in the money market and the stock is given by $(\alpha(t), \theta(t))$ where $\alpha(t)$ denotes the shares of the money market held and $\theta(t)$ denotes the shares of the stock held.

\section{A.2.1 Interest and Dividend Taxation}

The investor faces three forms of taxation in our analysis: interest taxation, dividend taxation, and capital gain taxation. Interest income is taxed as ordinary income at the constant rate $\tau_{I}$, while dividend income is taxed at the constant rate $\tau_{D}$. The total taxes paid on interest and dividend income at time $t$ are

$$
\Phi_{I, D}(t)=\tau_{I} \alpha(t-1) S_{0}(t-1)(\exp (r)-1)+\tau_{D} \theta(t-1) S_{1}(t-1) \delta
$$

If the investor dies at time $t$, interest and dividend taxes are still paid.

\section{A.2.2 Capital Gain Taxation}

Using our two definitions of capital gain taxation, realized capital gains and losses in the stock are subject to a constant capital gain tax rate of $\tau_{C}$. Computing the capital gain taxes due each period requires keeping track of the past purchase prices of the stock which forms the stock's tax basis. In our setting, the tax basis for the stock is calculated as a weighted-average purchase price for tractability. Let $B(t)$ denote the nominal tax basis of stock 1 after trading at time $t$. The stock basis evolves as

$$
B(t)= \begin{cases}S_{1}(t) & \text { if } \theta(t)=0 \text { or } \frac{B(t-1)}{S_{1}(t)}>1 \\ \frac{B(t-1) \theta(t-1)+(\theta(t)-\theta(t-1))^{+} S_{1}(t)}{\theta(t-1)+(\theta(t)-\theta(t-1))^{+}} & \text {otherwise }\end{cases}
$$

where $x^{+} \triangleq \max (x, 0)$. If $\theta(t)=0$, the basis resets to the current stock price, $B(t)=S_{1}(t)$. Here we have assumed that the investor is precluded from short-selling the stock.

Under the FUL case, any realized capital gains or losses are subject to capital gain taxation. The capital gain taxes $\Phi_{C G}^{F U L}(t)$ at time $t$ under the FUL case are

$$
\begin{aligned}
\Phi_{C G}^{F U L}(t)= & \tau_{C}\left(\left(S_{1}(t)-B(t-1)\right) \theta(t-1) \mathbf{1}_{\left\{B(t-1)>S_{1}(t)\right\}}\right. \\
& \left.+\left(S_{1}(t)-B(t-1)\right) \mathbf{1}_{\left\{B(t-1) \leq S_{1}(t)\right\}}(\theta(t-1)-\theta(t))^{+}\right),
\end{aligned}
$$

where the first line calculates capital losses from tax-loss selling the stock and the second line calculates taxes from selling stock with a capital gain. If death occurs at some time $t^{\prime}$, all capital gain taxes are forgiven implying $\Phi_{C G}^{F U}\left(t^{\prime}\right)=0$.

While the FUL case allows for negative taxes, or a tax rebate to be paid when capital losses are realized, the LUL case eliminates all tax rebates. Realized capital losses can only be used to offset 
current or future realized capital gains. As a result, an additional state variable, the accumulated capital loss $L(t)$, which measures accumulated but unused realized capital losses as of time $t$, is required. This state variable evolves as

$$
L(t)= \begin{cases}L(t-1)-\theta(t-1)\left(S_{1}(t)-B(t-1)\right) & \text { if } \frac{B(t-1)}{S_{1}(t)}>1 \\ \left\{L(t-1)-(\theta(t-1)-\theta(t))^{+}\left(S_{1}(t)-B(t-1)\right)\right\}^{+} & \text {otherwise }\end{cases}
$$

where $x^{+} \triangleq \max (x, 0) . L(t)$ is modelled as a nonnegative state variable. A positive value is interpreted as unused realized capital losses. The first line of (A.6) captures any increase in accumulated capital losses due to tax-loss selling. Based on Gallmeyer and Srivastava (2003), the investor is always weakly better off realizing a capital loss today even if he cannot use it immediately. This feature simplifies our analysis in that an extra state variable is not needed that tracks capital losses still inside the portfolio. The second line of (A.6) captures any decline in accumulated capital losses that are used to offset realized capital gains when shares are sold at time $t$.

Under the LUL case, only realized capital gains are subject to capital gain taxation. Realized capital losses are used to offset future realized gains. The capital gain taxes $\Phi_{C G}^{L U L}(t)$ at time $t$ under the LUL case are

$$
\Phi_{C G}^{L U L}(t)=\tau_{C}\left\{\left(S_{1}(t)-B(t-1)\right)^{+}(\theta(t-1)-\theta(t))^{+}-L(t-1)\right\}^{+}
$$

where capital gain taxes are paid when the investor realizes a capital gain and does not have a large enough accumulated capital loss $L(t-1)$ to offset that gain. If death occurs at some time $t^{\prime}$, all capital gain taxes are forgiven implying $\Phi_{C G}^{L U L}\left(t^{\prime}\right)=0$.

\section{A.2.3 Trading Strategies}

We now define the set of admissible trading strategies when the investor can invest in the stock and the riskless money market. Again, we assume that the investor is prohibited from shorting any security.

Letting $W(t+1)$ denote the time $t+1$ wealth before portfolio rebalancing and any capital gain taxes are paid, but after dividend and interest taxes are paid, $W(t+1)$ is given by

$$
\begin{aligned}
W(t+1)= & \alpha(t) S_{0}(t)\left(\left(1-\tau_{I}\right) \exp (r)+\tau_{I}\right) \\
& +\theta_{1}(t)\left(S_{1}(t+1)+S_{1}(t) \delta_{1}\left(1-\tau_{D}\right)\right),
\end{aligned}
$$

where (A.3) has been substituted. Given that no resources are lost when rebalancing the portfolio at time $t, W(t)$ is given by

$$
W(t)=\alpha(t) S_{0}(t)+\theta_{1}(t) S_{1}(t)+C(t)+\Phi_{C G}^{i}(t), \quad i \in\{F U L, L U L\},
$$

where $C(t)>0$ is the time $t$ consumption. 
Substituting (A.9) into (A.8) gives the dynamic after-tax wealth evolution of the investor,

$$
\begin{aligned}
& W(t+1)= \\
& \quad\left(W(t)-\theta(t) S_{1}(t)-C(t)-\Phi_{C G}^{i}(t)\right)\left(\left(1-\tau_{I}\right) \exp (r)+\tau_{I}\right) \\
& \quad+\theta(t)\left(S_{1}(t+1)+S_{1}(t) \delta_{1}\left(1-\tau_{D}\right)\right), \quad i \in\{F U L, L U L\} .
\end{aligned}
$$

An admissible trading strategy is a consumption and a security trading policy $(C, \alpha, \theta)$ such that for all $t, C(t) \geq 0, W(t) \geq 0, \theta(t) \geq 0$, and (A.10) is satisfied. The set of admissible trading strategies is denoted $\mathcal{A}$.

\section{A.2.4 Investor's Objective}

The investor's objective is to maximize his discounted expected utility of real lifetime consumption and final-period wealth at the time of death by choosing an admissible trading strategy given an initial endowment. If death occurs on date $t$, the investor's assets totaling $W(t)$ are liquidated and used to purchase a perpetuity that pays to his heirs a constant real after-tax cash flow of $R^{*} W(t)$ each period starting on date $t+1$. The quantity $R^{*}$ is the one-period after-tax real riskless interest rate computed using simple compounding. In terms of the instantaneous nominal riskless money market rate $r$ and the instantaneous inflation rate $i, R^{*}$ is defined by

$$
R^{*}=\left(\left(1-\tau_{D}\right) \exp (r)+\tau_{D}\right) \exp (-i)-1
$$

Under the assumption that the investor and his heirs have identical preferences of the constant relative risk aversion (CRRA) form with a coefficient of relative risk aversion of $\gamma$ and a common time preference parameter $\beta$, the investor's optimization problem is given by

$$
\begin{aligned}
\max _{(C, \alpha, \theta) \in \mathcal{A}} E\left[\sum _ { t = 0 } ^ { T } \beta ^ { t } \left\{\frac{H(t)}{1-\gamma}(\exp (-i t) C(t))^{1-\gamma}\right.\right. & \\
& \left.\left.+\frac{H(t-1)-H(t)}{1-\gamma} \sum_{s=t+1}^{\infty} \beta^{s-t}\left(\exp (-i t) R^{*} W(t)\right)^{1-\gamma}\right\}\right] .
\end{aligned}
$$

The objective function captures the expected utility of future real consumption as well as the bequest motive to the investor's heirs.

Since $\sum_{s=t+1}^{\infty} \beta^{s-t}=\frac{\beta}{1-\beta}$, the investor's objective function simplifies, leading to the optimization problem

$$
\begin{aligned}
\max _{\left(C, \alpha, \theta_{1}, \theta_{2}\right) \in \mathcal{A}} E\left[\sum _ { t = 0 } ^ { T } \beta ^ { t } \left\{\frac{H(t)}{1-\gamma}(\exp (-i t) C(t))^{1-\gamma}\right.\right. & \\
& \left.\left.+\frac{H(t-1)-H(t)}{1-\gamma} \frac{\beta}{1-\beta}\left(\exp (-i t) R^{*} W(t)\right)^{1-\gamma}\right\}\right] .
\end{aligned}
$$




\section{A.3 Change of Variables}

As in a no-tax portfolio choice problem with CRRA preferences, the optimization problem (A.12) is homogeneous in wealth, and thus independent of the investor's initial wealth. To show that wealth is not needed as a state variable when solving (A.12), we express the optimization problem's controls as being proportional to time $t$ wealth $W(t)$ before trade has occurred but after dividend and interest taxes have been paid. We define

$$
\underline{\pi}(t) \triangleq \frac{S_{1}(t) \theta(t-1)}{W(t)}, \quad \bar{\pi}(t) \triangleq \frac{S_{1}(t) \theta(t)}{W(t)},
$$

where $\underline{\pi}(t)$ and $\bar{\pi}(t)$ are the proportions of stock owned entering and leaving period $t$, with respect to time $t$ wealth $W(t)$. Note that the investor will never choose a trading strategy that leads to a non-positive wealth at any time given our utility function choice, the bequest motive, and the positive probability of death over each period. Hence, we can define portfolio weights as $W(t)>0$ for all $t$.

Using (A.13), it is useful to express the basis $B(t)$ as a basis-price ratio $b(t+1) \triangleq \frac{B(t)}{S_{1}(t+1)}$. Using (A.4), the basis-price ratio evolves as

$$
b(t+1)= \begin{cases}\frac{S_{1}(t)}{S_{1}(t+1)} & \text { if } \underline{\pi}(t)=0 \text { or } b(t)>1 \\ \frac{b(t) \underline{\pi}(t)+(\bar{\pi}(t)-\underline{\pi}(t))^{+}}{\frac{S_{1}(t+1)}{S_{1}(t)}\left(\underline{\pi}(t)+(\bar{\pi}(t)-\underline{\pi}(t))^{+}\right)} & \text {otherwise. }\end{cases}
$$

If $\bar{\pi}(t)=0$, the basis-price ratio $b(t+1)$ resets to the ratio of the time $t$ and $t+1$ stock price, $b(t+1)=\frac{S_{1}(t)}{S_{1}(t+1)}$. The basis-price ratio at time $t+1$ can be expressed as a function of the capital gain of stock $i$ over one period $\frac{S_{1}(t+1)}{S_{1}(t)}$, the previous period's basis-price ratio $b(t)$, and the equity proportions $\bar{\pi}(t)$ and $\underline{\pi}(t)$.

For the LUL case, the accumulated loss state variable $L(t)$ must also be expressed proportional to $W(t)$. Similar to the stock position, we define

$$
\underline{l}(t) \triangleq \frac{L(t-1)}{W(t)}, \quad \bar{l}(t) \triangleq \frac{L(t)}{W(t)},
$$

where $\underline{l}(t)$ and $\bar{l}(t)$ are the proportions of accumulated capital losses entering and leaving period $t$, with respect to time $t$ wealth $W(t)$.

Using (A.6), the proportional accumulated capital losses evolve as

$$
\bar{l}(t)= \begin{cases}\underline{l}(t)-\underline{\pi}(t)(1-b(t)) & \text { if } b(t)>1, \\ \left\{\underline{l}(t)-(\underline{\pi}(t)-\bar{\pi}(t))^{+}(1-b(t))\right\}^{+} & \text {otherwise }\end{cases}
$$

where $x^{+} \triangleq \max (x, 0)$. Note that this quantity is independent of wealth $W(t)$.

Using the equity proportions, the basis-price ratios, and the proportional accumulated capital losses, the total capital gain taxes paid at time $t, \Phi_{C G}^{i}(t)$, can be written proportional to $W(t)$, 
$\Phi_{C G}^{i}(t)=W(t) \phi_{C G}^{i}(t), i \in\{F U L, L U L\}$ where $\phi_{C G}^{i}(t)$ is independent of $W(t)$, since each component of the total capital gain taxes paid can be written proportional to $W(t)$. For the FUL case,

$$
\phi_{C G}^{F U L}(t)=\tau_{C}\left((1-b(t)) \underline{\pi}(t) \mathbf{1}_{\{b(t)>1\}}+\left((1-b(t)) \mathbf{1}_{\{b(t) \leq 1\}}(\underline{\pi}(t)-\bar{\pi}(t))^{+}\right) .\right.
$$

For the LUL case,

$$
\phi_{C G}^{L U L}(t)=\tau_{C}\left\{(1-b(t))^{+}(\underline{\pi}(t)-\bar{\pi}(t))^{+}-\underline{l}(t)\right\}^{+} .
$$

Given that no resources are lost when portfolio rebalancing and paying taxes, equation (A.9) implies that the money market investment $\alpha(t) S_{0}(t)$ can be written proportional to $W(t)$ :

$$
\alpha(t) S_{0}(t)=W(t)\left(1-\bar{\pi}(t)-c(t)-\phi_{C G}^{i}(t)\right), \quad i \in\{F U L, L U L\}
$$

where $c(t) \triangleq \frac{C(t)}{W(t)}$.

The wealth evolution equation (A.10) can also be written proportional to $W(t)$ implying

$$
\begin{aligned}
\frac{W(t+1)}{W(t)}= & \frac{1}{1-\underline{\pi}(t+1)}\left[\left(\left(1-\tau_{D}\right) \exp (r)+\tau_{D}\right)\left(1-\bar{\pi}(t)-c(t)-\phi_{C G}^{i}(t)\right)\right. \\
& \left.+\bar{\pi}(t) \delta\left(1-\tau_{D}\right)\right], \quad i \in\{F U L, L U L\} .
\end{aligned}
$$

Additionally, the stock proportion evolution and the accumulated capital loss evolution are given by

$$
\underline{\pi}(t+1)=\frac{\frac{S_{1}(t+1)}{S_{1}(t)} \bar{\pi}(t)}{\frac{W(t+1)}{W(t)}}, \quad \underline{l}(t+1)=\frac{\bar{l}(t)}{\frac{W(t+1)}{W(t)}},
$$

where both quantities are independent of time $t$ wealth. This evolution is needed in the dynamic programming formulation of the investor's problem. In particular, $\underline{\pi}$ is a state variable and $\bar{\pi}$ is a control variable.

Using the principle of dynamic programming and substituting out $W(t)$, the Bellman equation for the investor's optimization problem (A.12) in the FUL case is summarized by three state variables and is given by

$$
\begin{array}{r}
V(t, \underline{\pi}(t), b(t))= \\
\max _{c(t), \bar{\pi}(t)} \frac{e^{-\lambda_{t}} c(t)^{1-\gamma}}{1-\gamma}+\frac{\left(1-e^{-\lambda_{t}}\right) \beta\left(R^{*}\right)^{1-\gamma}}{(1-\beta)(1-\gamma)}+e^{-\lambda_{t}} \beta E_{t}\left[\left(\frac{e^{-i} W(t+1)}{W(t)}\right)^{(1-\gamma)} \times\right. \\
V(t+1, \underline{\pi}(t+1), b(t+1))],
\end{array}
$$

for $t=0,1, \ldots, T-1$ subject to the wealth evolution equation (A.20) and the stock proportion dynamics (A.21). In the LUL case, an additional state variable is needed, $\underline{l}$, the accumulated capital 
losses. The Bellman equation for this investor's problem is given by

$$
\begin{array}{r}
V(t, \underline{\pi}(t), b(t), \underline{l}(t))= \\
\max _{c(t), \bar{\pi}(t), \underline{l}(t)} \frac{e^{-\lambda_{t}} c(t)^{1-\gamma}}{1-\gamma}+\frac{\left(1-e^{-\lambda_{t}}\right) \beta\left(R^{*}\right)^{1-\gamma}}{(1-\beta)(1-\gamma)}+e^{-\lambda_{t}} \beta E_{t}\left[\left(\frac{e^{-i} W(t+1)}{W(t)}\right)^{(1-\gamma)} \times\right. \\
V(t+1, \underline{\pi}(t+1), b(t+1), \underline{l}(t+1))],
\end{array}
$$

for $t=0,1, \ldots, T-1$ subject to the wealth evolution equation (A.20) and the stock/capital loss proportion dynamics (A.21).

\section{B Numerical Optimization}

The value functions (A.22) and (A.23) are solved numerically through backward recursion starting at time $T$. The optimization problem is 80 years long with annual time steps and two choice variables. For the LUL case, the state variables are the beginning-of-period stock allocation $(\underline{\pi}(t))$, the beginning-of-period tax basis $(b(t))$, and the beginning-of-period unused capital loss $(\underline{l}(t))$. The FUL case has one less state variable as the beginning-of-period unused capital loss $(\underline{l}(t))$ is not needed.

On each point on the grid of state variables we solve an optimization problem for two choice variables: the optimal consumption level and the wealth allocation in the stock $(c(t), \bar{\pi}(t))$. We search for the optimal allocation using a grid, in a recursive manner (coarse grid to fine grid). Specifically, for each period and each point in the state variable grid, an initial coarse grid in consumption levels and wealth allocation in equity is searched for the choice variable values that maximize the value function. Subsequently the search grid is refined around the choice variable points with the highest level of the value function. The procedure is repeated until the size of the dimensions of the grid are smaller than some required level of accuracy. The accuracy used in the optimizations reported in the paper was 10 basis points in the optimal equity wealth allocation and 1 basis point in the consumption level. The state variables for each period are discretized with a discretization step of $5 \%$ both for the tax basis and the wealth allocation in each asset. Due to

the discrete nature of the state variable grid, and the arbitrary positions taken when exploring the set of allowed values in the choice variables, we interpolate the value function on the state variable grid. The interpolation algorithm we use relies on first scaling the value function by the appropriate wealth-related factor, and on linear interpolation of the resulting deflated value function. 


\section{References}

Cadenillas, A., and S. R. Pliska, 1999, "Optimal Trading of a Security When There Are Taxes and Transaction Costs," Finance and Stochastics, 3(2), February, 137-165.

Constantinides, G., 1983, "Capital Market Equilibrium with Personal Tax," Econometrica, 51, 611636.

Dammon, R., and C. Spatt, 1996, "The Optimal Trading and Pricing of Securities with Asymmetric Capital Gains Taxes and Transaction Costs," Review of Financial Studies, 9, 921-952.

Dammon, R., C. Spatt, and H. Zhang, 2001a, "Diversification and Capital Gains Taxes with Multiple Risky Assets," November, Carnegie Mellon University.

Dammon, R., C. Spatt, and H. Zhang, 2001b, "Optimal Consumption and Investment with Capital Gains Tax," Review of Financial Studies, 14(3), 583-616.

Dammon, R., C. Spatt, and H. Zhang, 2004, "Optimal Asset Location and Allocation with Taxable and Tax-Deferred Investing," Journal of Finance, 59(3), 999-1037.

DeMiguel, V., and R. Uppal, 2005, "Portfolio Investment with the Exact Tax Basis via Nonlinear Programming," Management Science, 55(2), 277-290.

Dybvig, P., and H. K. Koo, 1996, "Investment with Taxes," Washington University.

Gallmeyer, M., and S. Srivastava, 2003, "Arbitrage and the Tax Code," Carnegie Mellon University.

Gallmeyer, M., S. Tompaidis, and R. Kaniel, 2006, "Tax Management Strategies with Multiple Risky Assets," Journal of Financial Economics, 80, 243-291.

Garlappi, L., L. V. Naik, and J. Slive, 2001, "Portfolio Selection with Multiple Assets and Capital Gains Taxes," University of British Columbia.

Huang, J., 2001, "Taxable or Tax-Deferred Account? Portfolio Decisions with Multiple Investment Goals," MIT Sloan School of Management.

Hur, S.-K., 2001, “Optimal Portfolio Selection with Personal Tax," University of Chicago.

Jouini, E., P.-F. Koehl, and N. Touzi, 2000, "Optimal Investment with Taxes: An Existence Result," Journal of Mathematical Economics, 33(4), May, 373-388.

Marekwica, M., 2007, "Optimal Tax-Timing and Asset Allocation when Tax Rebates on Capital Losses are Limited," working paper, Goethe University, July.

Poterba, J. M., 2001, "Taxation, Risk-Taking, and Household Portfolio Behavior," in Handbook of Public Economics (vol. 3). 
Figure 1: Example - Allocations. The left (right) panels summarize after-tax optimal portfolio choice as a function of the investor's basis-to-price ratio at time $t=0$ in number of shares (fraction of wealth). The top panels present the after-trade portfolio choice at $t=0$, the middle panels present the after-trade portfolio at $t=1$ when the stock goes up, and the bottom panels present after-trade portfolio at $t=1$ when the stock goes down. The parameters used are given at the beginning of Section 3 .
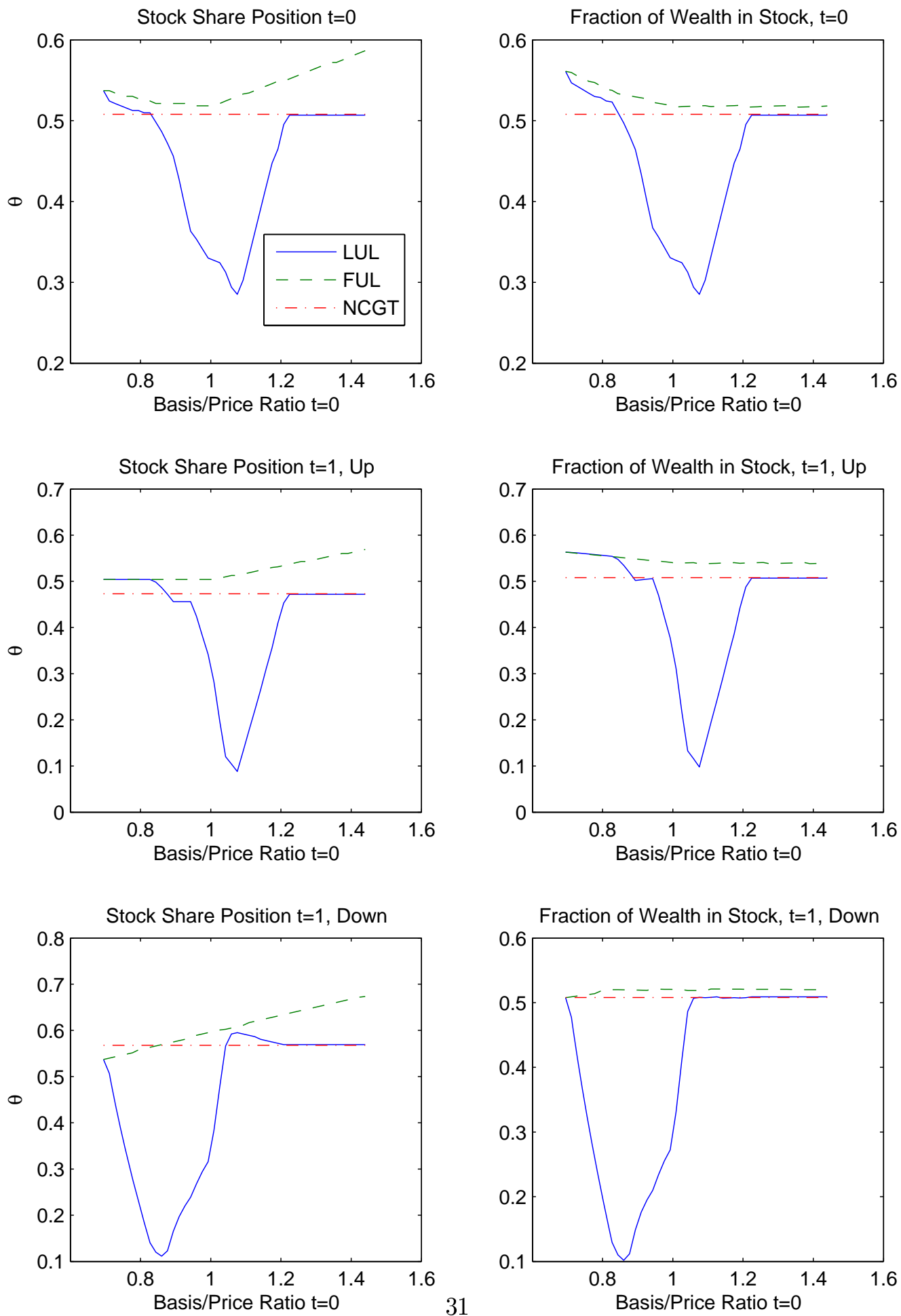
Figure 2: Example - Wealths and Expected Utility. The figure reports the after-trade wealths at $t=0$ (top left panel), $t=1$ (middle left panels), and $t=2$ (right panels) as well as the time $t=0$ expected utility (bottom left panel). For the $t=2$ wealth plots (right panels), each is labeled by the stock path taken. For example, the plot labeled "Up, Down" is for a rise in the stock price at $t=1$ and a drop in the stock price at $t=2$. All quantities are plotted as a function of the investor's time $t=0$ basis-to-price ratio. The parameters used are given at the beginning of Section 3 .
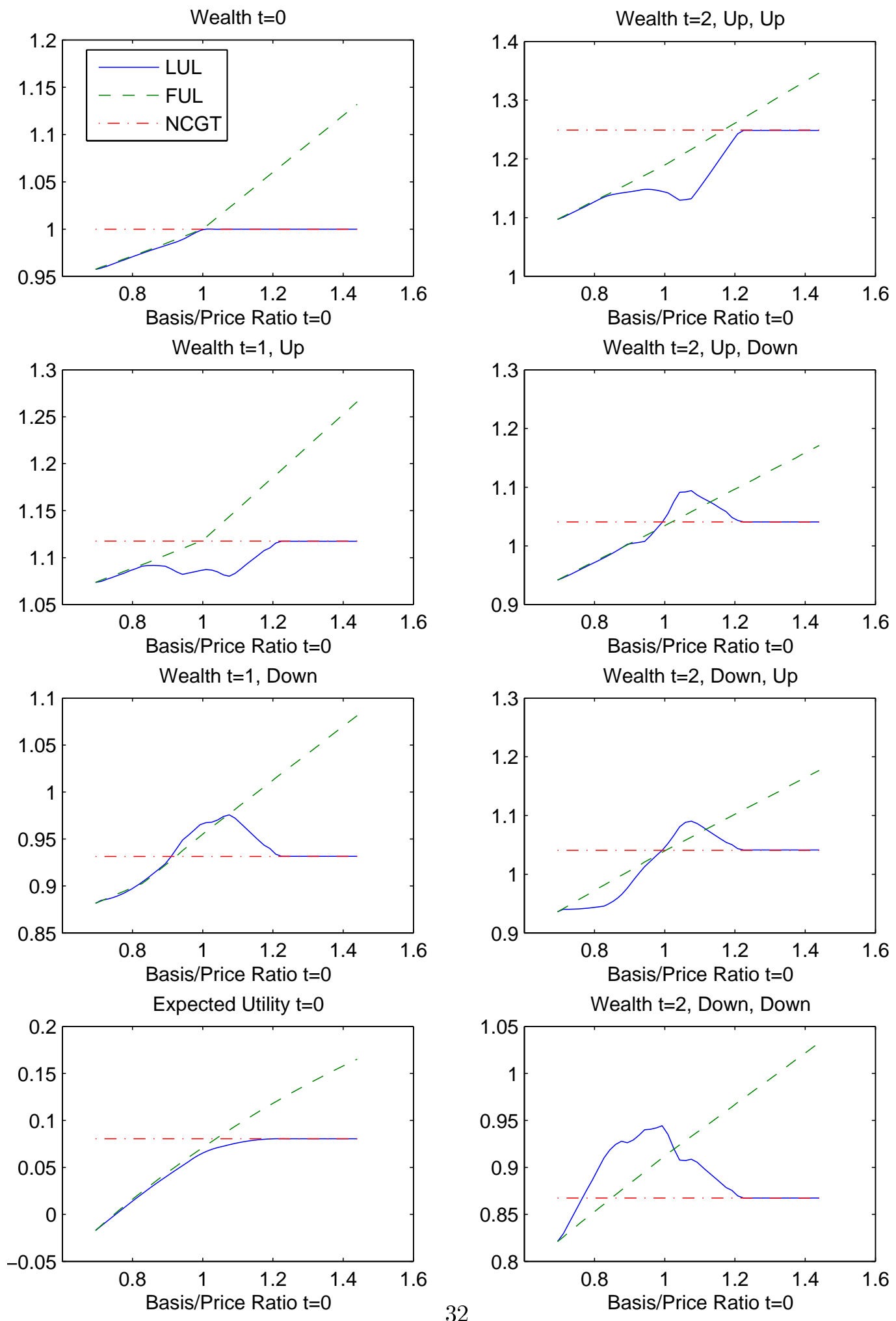
Figure 3: Example - Taxes. The figure reports the capital gain taxes paid at $t=0$ (top left panel), $t=1$ (middle left panels), and $t=2$ (right panels). For the $t=2$ capital gain tax plots (right panels), each is labeled by the stock path taken. For example, the plot labeled "Up, Down" is for a rise in the stock price at $t=1$ and a drop in the stock price at $t=2$. All quantities are plotted as a function of the investor's time $t=0$ basis-to-price ratio. The parameters used are given at the beginning of Section 3 .
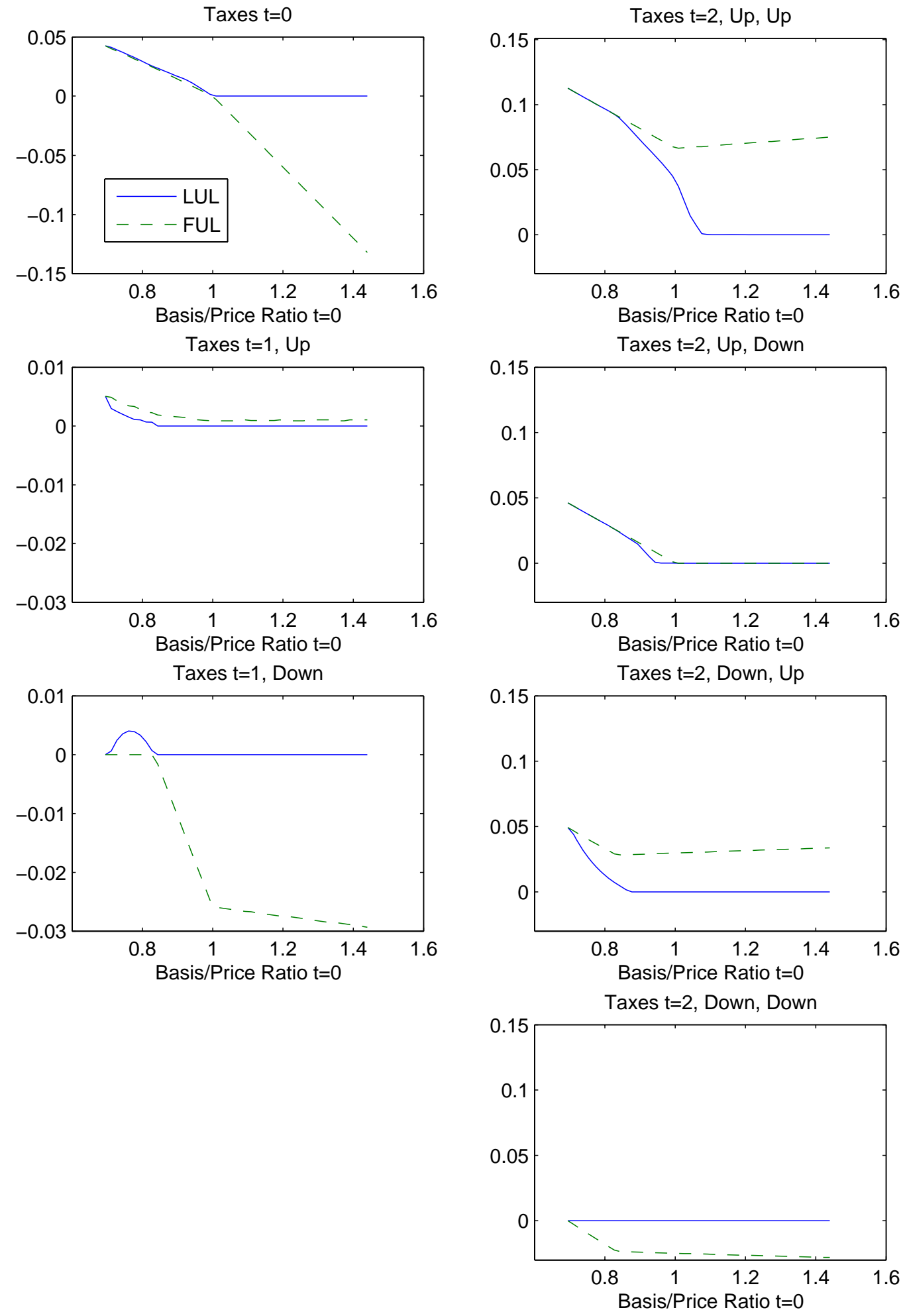
Figure 4: Base Case Optimal Strategies. The left (right) panels summarize optimal portfolio choice as a function of the asset allocation and the basis-to-price ratio entering the trading period for the FUL (LUL) case. The top (bottom) panels present the stock-to-wealth ratio at age 20 (80). The LUL plots have a zero carry-over loss entering the trading period. The parameters used are the Base Case parameters summarized in Section 2.4.

Basecase, Full Realization, Age 20
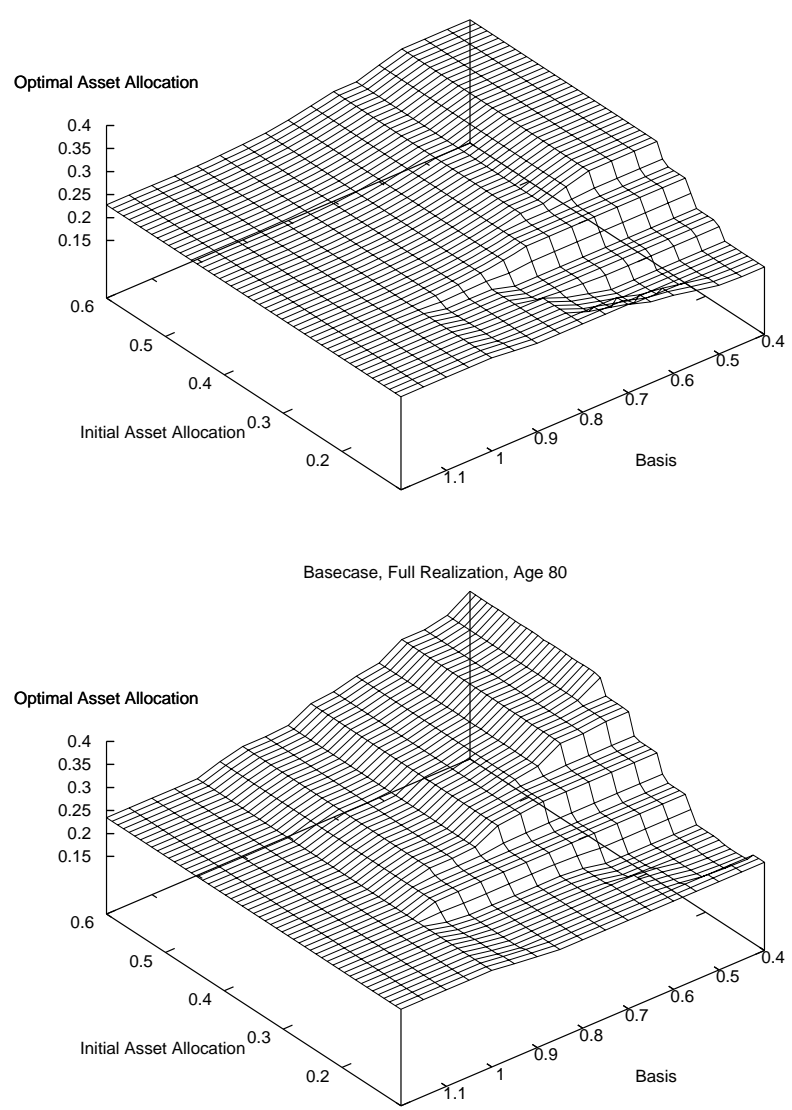

Basecase, Carry-over Losses 0\%, Age 20
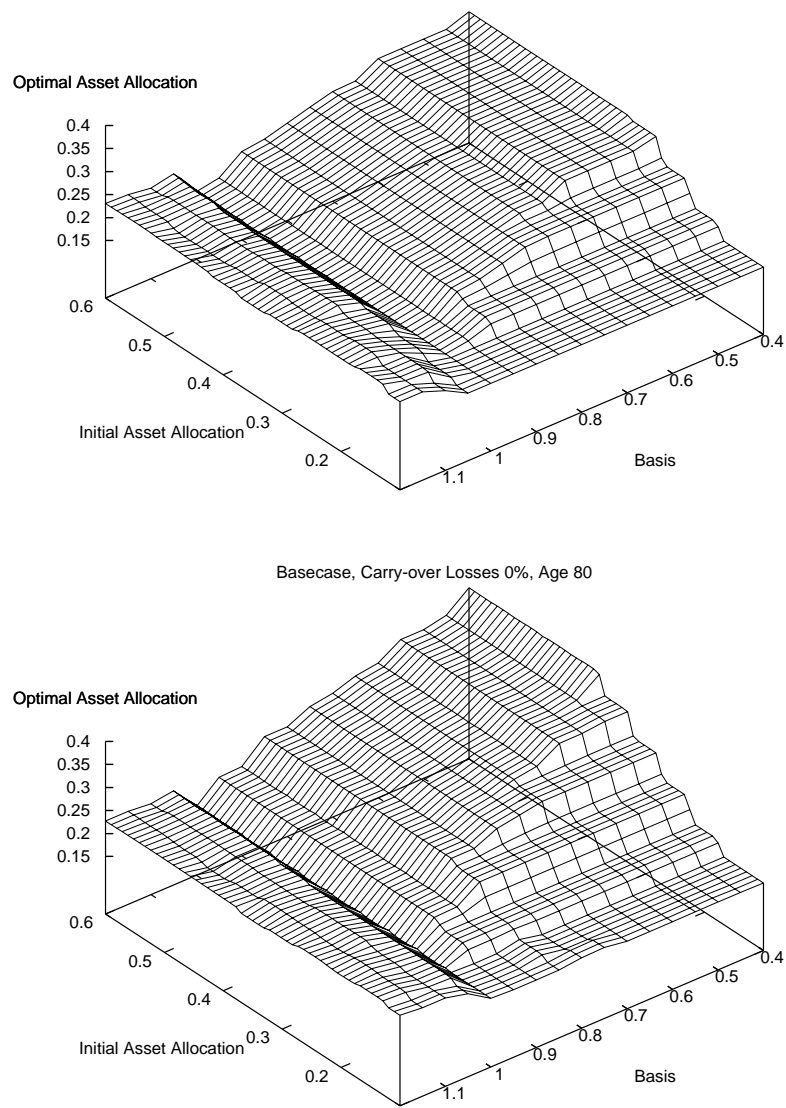


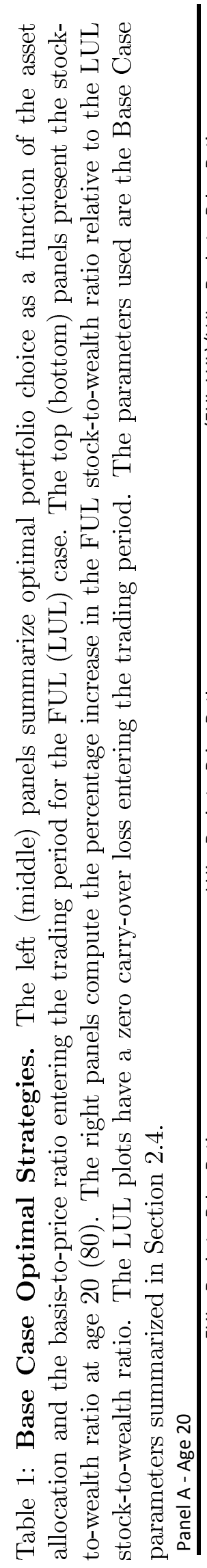

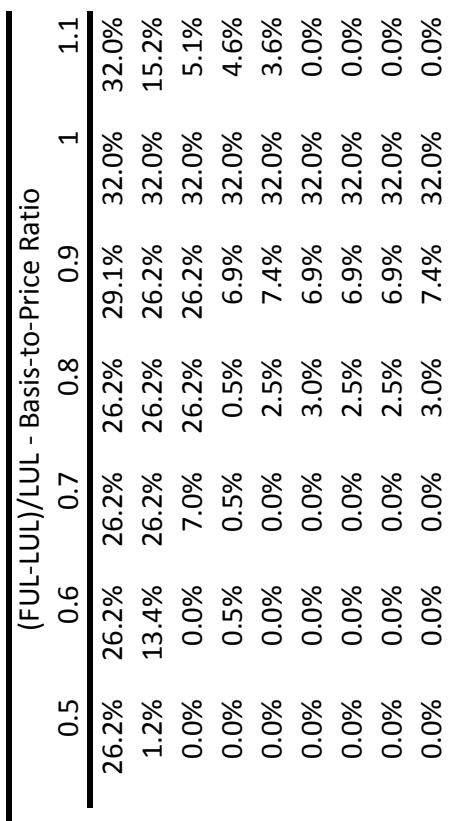

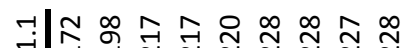
न彳ं $-\pi \leqslant \leqslant \leqslant \leqslant \leqslant \leqslant \leqslant \leqslant N$

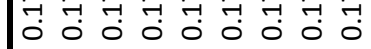

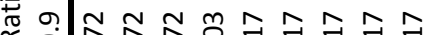
ঞ

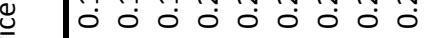
$=\infty N N N N N G N-0$

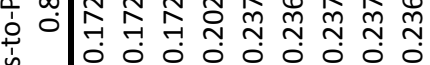
D $N \sim N \sim m m m m$

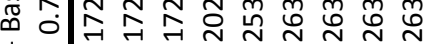

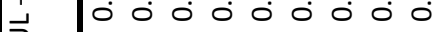

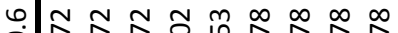

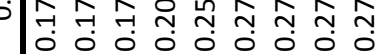

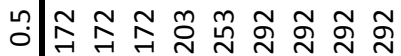
|⿹丁口

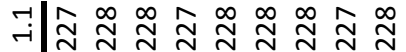

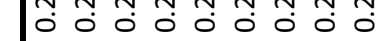

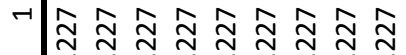
- $\quad 0000000000$ ণ ษ 잉 i $0 \begin{array}{lllllllll}0 & 0 & 0 & 0 & 0 & 0 & 0 & 0 & 0\end{array}$ 范 $1 \quad 0 \quad 00000000$ 4 .

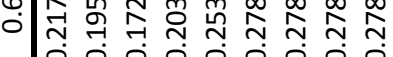

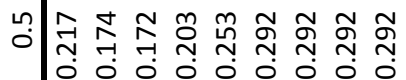

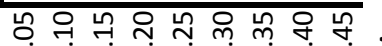
000000000

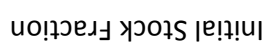

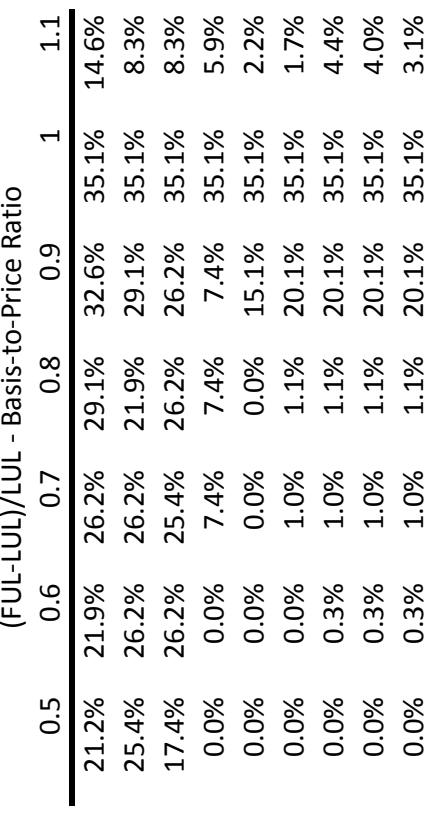

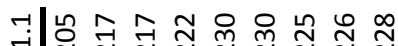
-

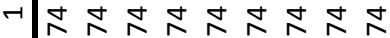
नㅁㅇㅇ

ol $N$ N 20000

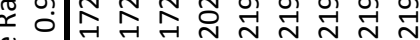
\& $=\infty \sim \infty N \sim N m m m m$

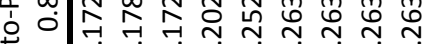

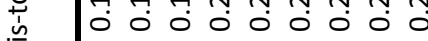

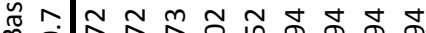

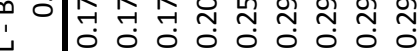
$00 N N$ N $m$ N N ○|न การ

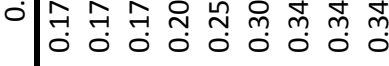

ت|ㅠㄹ

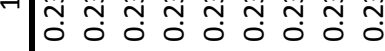

- 1 ᄂ

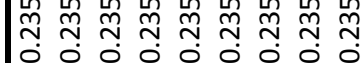
- $\quad 0000000000$ ণั \& 0 O $\infty$

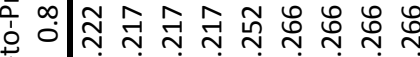

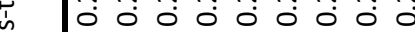

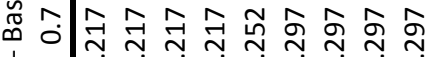
- 0 0 00000000

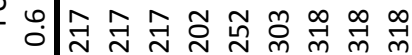
○ 000000000

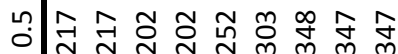
○ 000000000

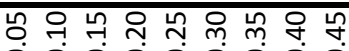

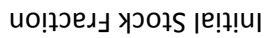




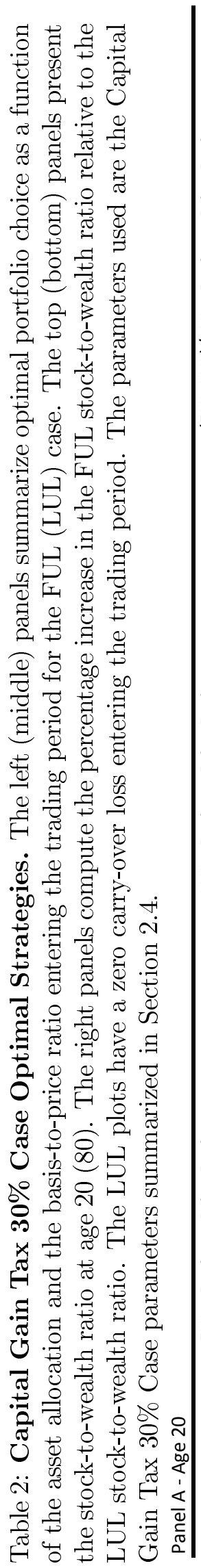

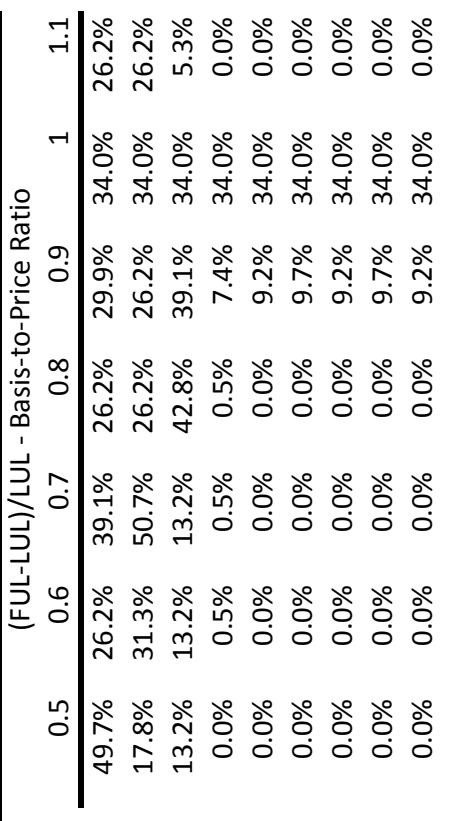

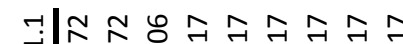
-

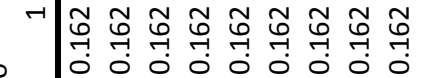
융

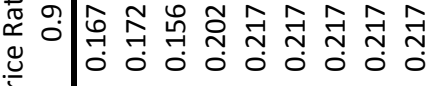

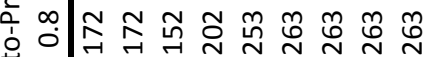

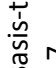

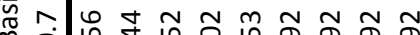

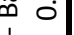
○

0

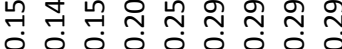

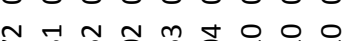

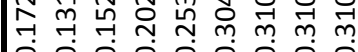
1000000000

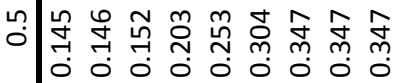

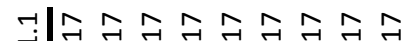

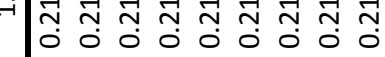
- 00000000000

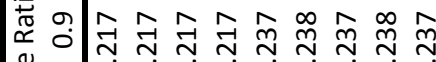
艾 市

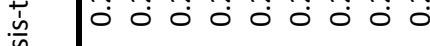

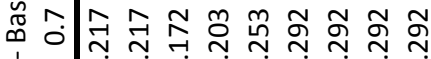
D 0000000000

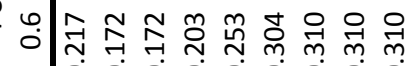

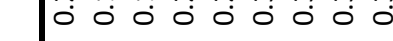
น ० 0000000000

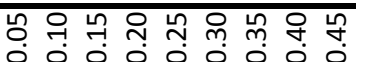

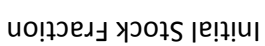

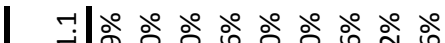
भं mं m户

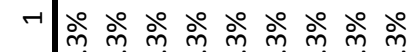
$\stackrel{\circ}{*}$

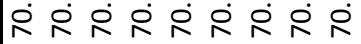

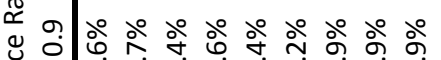
年

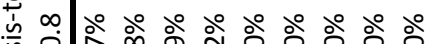

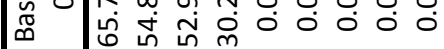

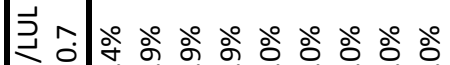
)

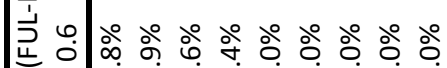
ที่ ก่

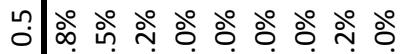

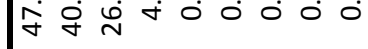

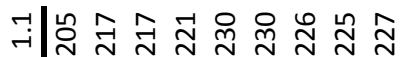
- 0 - 0 ก

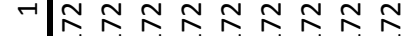
न1 का

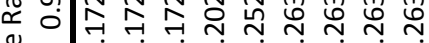
凹

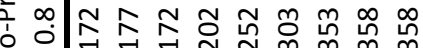
界 m.

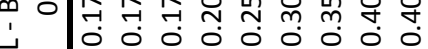
D $0 N N N N m m m$

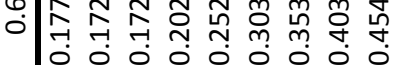

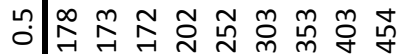
निं

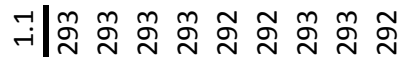

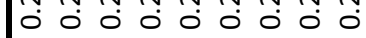
$\rightarrow m m m m m m m m$

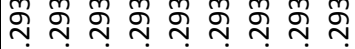
- 0 O 0 O 0 O

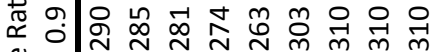
ษ

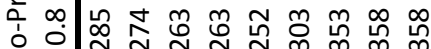

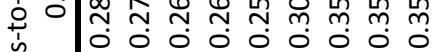
范

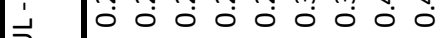
뭉 苍

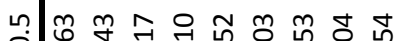

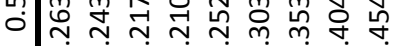

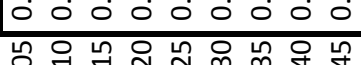
$\circ 00000000$

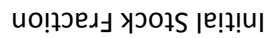




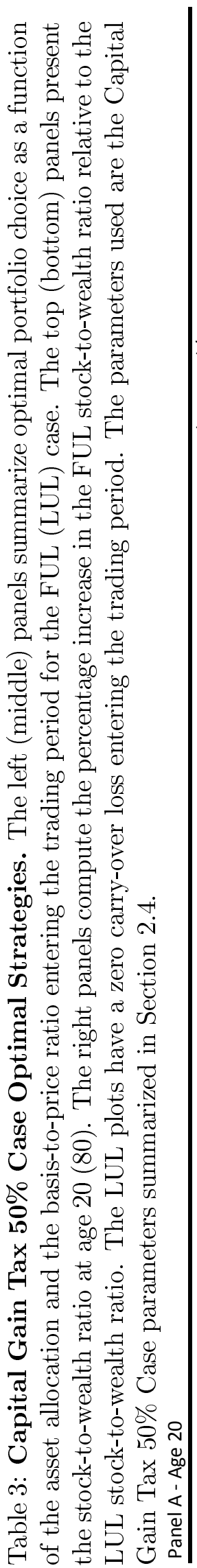

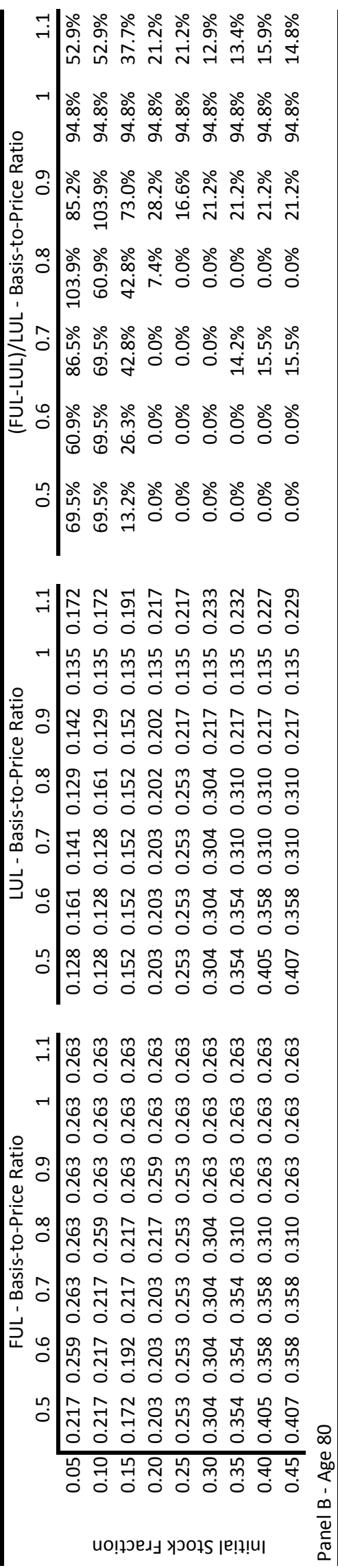

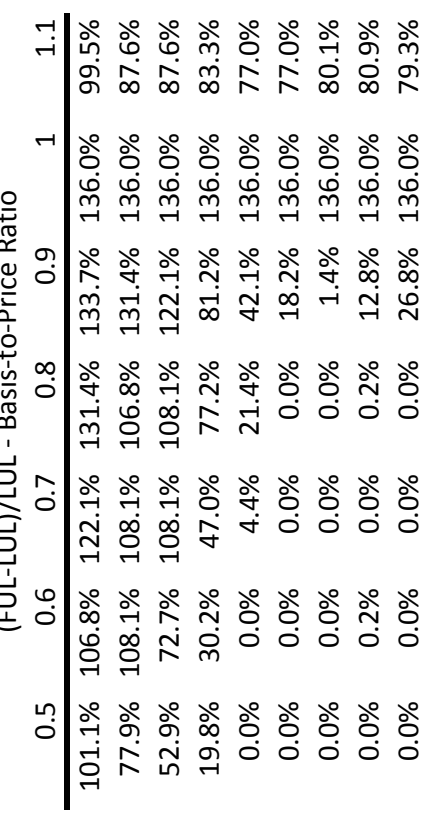

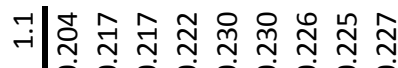

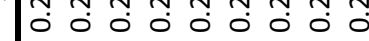

$-\pi N \leqslant N \leqslant N \leqslant N \leqslant \frac{5}{5}$ ન- ન્ન

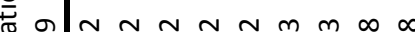

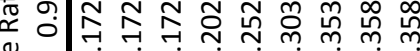
\&

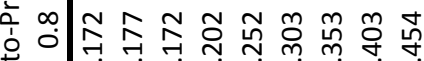

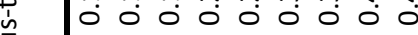

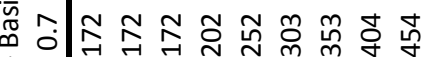
$-\quad 00000000000$

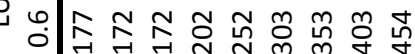
o 0000000000 นด

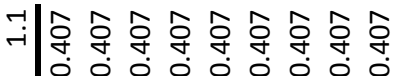
$r \ell \bullet \bullet \bullet \bullet \bullet \bullet \bullet$

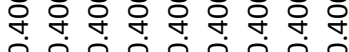
茫 \& 央 $\infty$ o ○ n

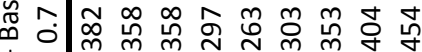
$\begin{array}{lllllllll}1 & 0 & 0 & 0 & 0 & 0 & 0 & 0 & 0\end{array}$

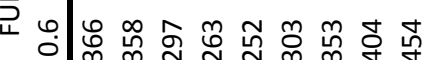

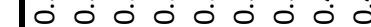

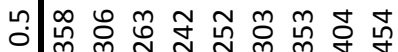

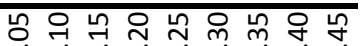
००००000000

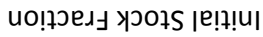



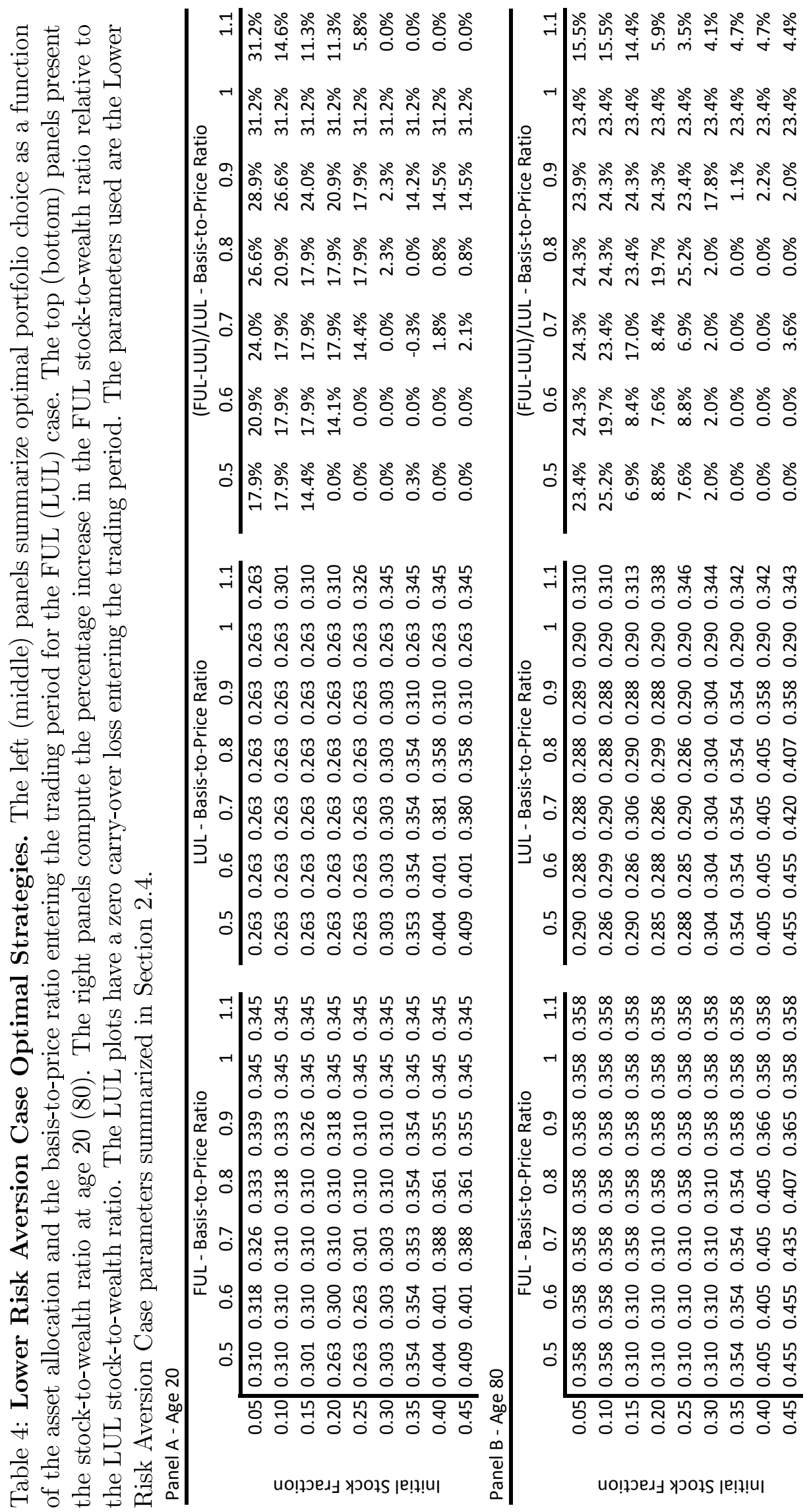


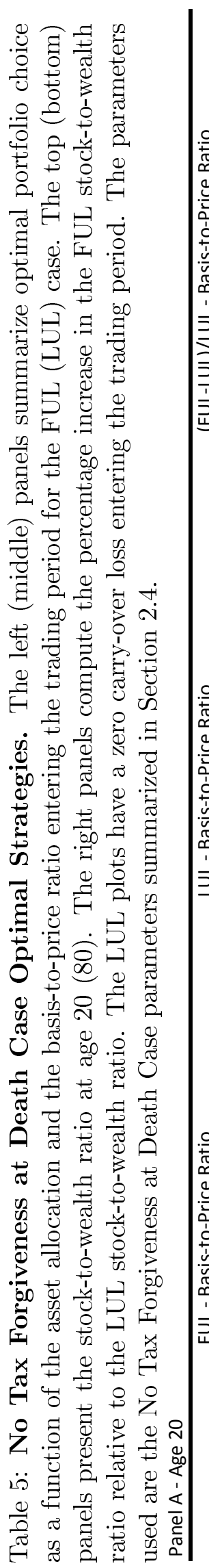

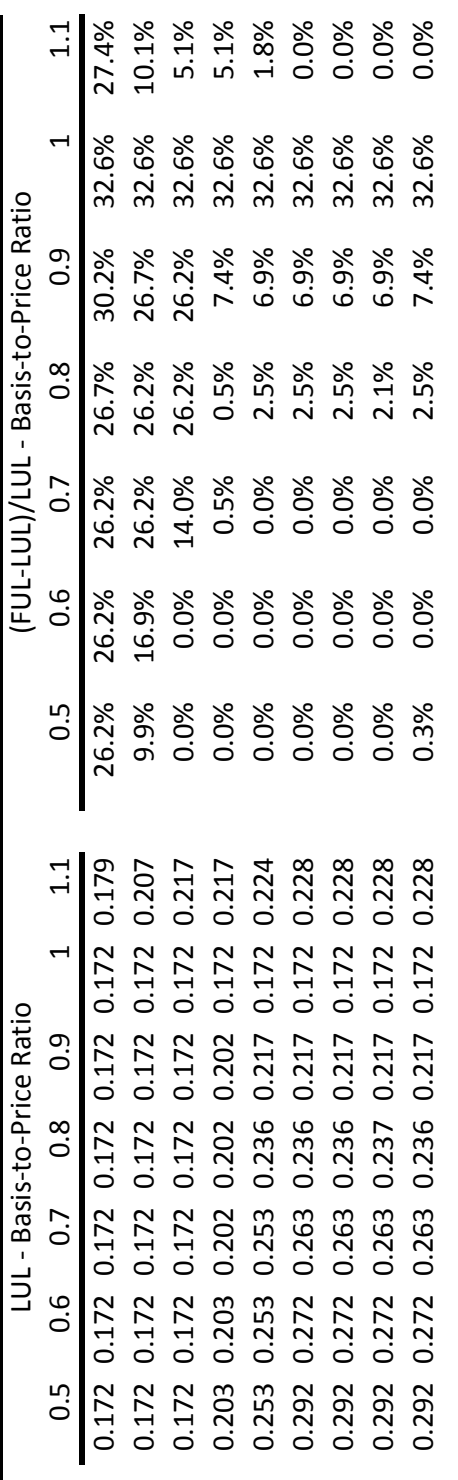

$\exists \mid \stackrel{\sim}{\sim} \stackrel{\infty}{\sim} \stackrel{\infty}{\sim} \stackrel{\infty}{\sim} \stackrel{\sim}{\sim} \stackrel{\infty}{\sim} \stackrel{\infty}{\sim} \stackrel{\sim}{\sim}$

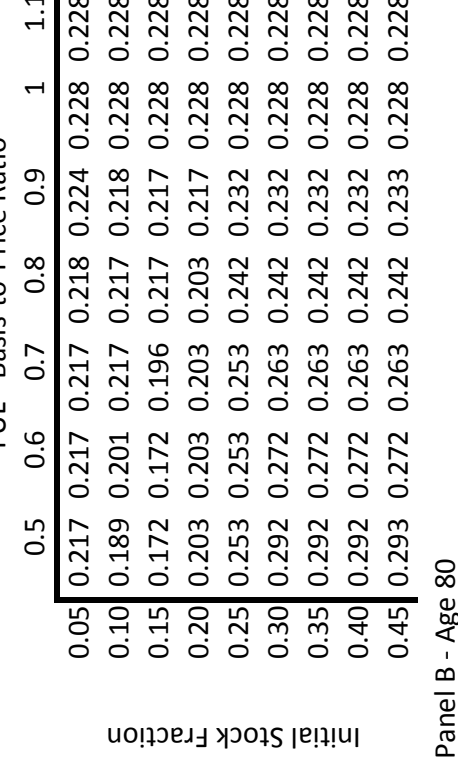

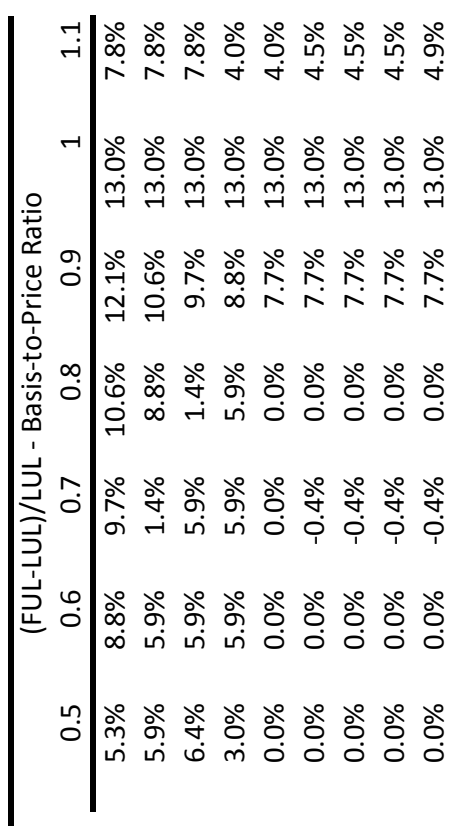

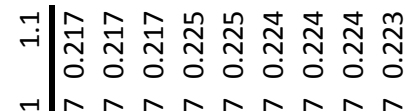

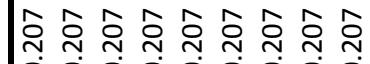
- $\quad 00000000000$

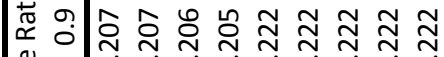
ษ

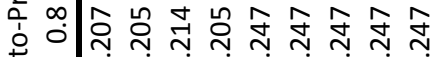

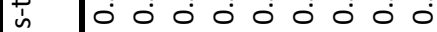

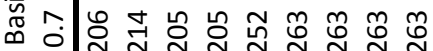
$-\quad 00000000000$

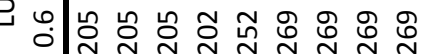

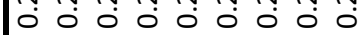

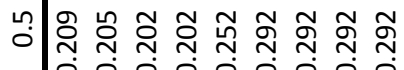
1000 000000

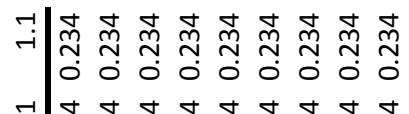

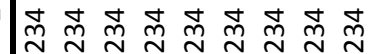
- 00000000 蛋

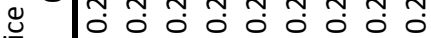
家

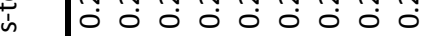
ळ $\begin{array}{lllllllll}0 & 0 & 0 & 0 & 0 & 0 & 0 & 0 & 0\end{array}$

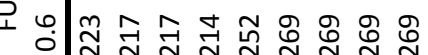
0000000000

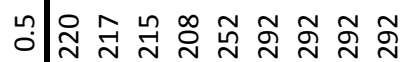

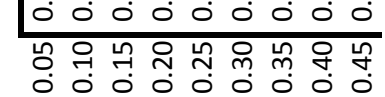

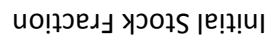


Table 6: Base Case Simulations. This table presents simulation results for portfolio characteristics under the FUL and the LUL cases at ages 40,60, and 80 over 50, 000 paths. The investor starts at age 20 with no embedded capital gains and zero carry-over loss (LUL cases). The parameters used are the Base Case parameters summarized in Section 2.4.

Panel A - Age 40

\begin{tabular}{|c|c|c|c|c|c|c|c|c|c|}
\hline \multirow[b]{2}{*}{ Percentile } & \multicolumn{2}{|c|}{ Wealth } & \multicolumn{2}{|c|}{$\begin{array}{c}\text { Stock-to-Wealth } \\
\text { Ratio }\end{array}$} & \multicolumn{2}{|c|}{$\begin{array}{l}\text { Basis-to-Price } \\
\text { Ratio }\end{array}$} & \multicolumn{2}{|c|}{$\begin{array}{c}\text { Cumulative Capital } \\
\text { Gain Tax-to-Wealth } \\
\text { Ratio }\end{array}$} & \multirow{2}{*}{$\begin{array}{l}\text { LUL Carry } \\
\text { Over Loss- } \\
\text { to-Wealth } \\
\text { Ratio }\end{array}$} \\
\hline & FUL & LUL & FUL & LUL & FUL & LUL & FUL & LUL & \\
\hline $10 \%$ & 151.0 & 153.3 & $21.0 \%$ & $18.3 \%$ & $15.0 \%$ & $15.7 \%$ & $-1.7 \%$ & $0.0 \%$ & $0.0 \%$ \\
\hline $20 \%$ & 164.2 & 164.4 & $22.2 \%$ & $19.7 \%$ & $21.6 \%$ & $22.1 \%$ & $-0.9 \%$ & $0.0 \%$ & $0.0 \%$ \\
\hline $30 \%$ & 176.6 & 174.2 & $22.7 \%$ & $21.4 \%$ & $26.7 \%$ & $27.5 \%$ & $-0.4 \%$ & $0.0 \%$ & $0.0 \%$ \\
\hline $40 \%$ & 184.8 & 182.6 & $24.6 \%$ & $22.6 \%$ & $35.1 \%$ & $35.6 \%$ & $-0.1 \%$ & $0.0 \%$ & $0.0 \%$ \\
\hline $50 \%$ & 194.4 & 190.0 & $25.8 \%$ & $23.7 \%$ & $41.0 \%$ & $41.9 \%$ & $0.2 \%$ & $0.1 \%$ & $0.0 \%$ \\
\hline $60 \%$ & 207.9 & 202.0 & $26.8 \%$ & $26.1 \%$ & $50.2 \%$ & $50.9 \%$ & $0.4 \%$ & $0.1 \%$ & $0.0 \%$ \\
\hline $70 \%$ & 218.5 & 213.0 & $29.3 \%$ & $28.6 \%$ & $59.6 \%$ & $60.2 \%$ & $0.6 \%$ & $0.3 \%$ & $0.0 \%$ \\
\hline $80 \%$ & 237.9 & 231.7 & $30.4 \%$ & $30.6 \%$ & $72.5 \%$ & $75.0 \%$ & $0.9 \%$ & $0.7 \%$ & $0.0 \%$ \\
\hline $90 \%$ & 269.1 & 261.5 & $34.3 \%$ & $34.7 \%$ & $89.1 \%$ & $90.2 \%$ & $1.6 \%$ & $1.4 \%$ & $0.0 \%$ \\
\hline Mean & 204.3 & 200.9 & $26.5 \%$ & $25.3 \%$ & $46.6 \%$ & $47.2 \%$ & $0.0 \%$ & $0.4 \%$ & $0.5 \%$ \\
\hline Std.Dev. & 48.6 & 46.1 & $4.8 \%$ & $5.8 \%$ & $26.6 \%$ & $26.8 \%$ & $1.4 \%$ & $0.6 \%$ & $2.7 \%$ \\
\hline \multicolumn{10}{|c|}{ Panel B - Age 60} \\
\hline & \multicolumn{2}{|c|}{ Wealth } & \multicolumn{2}{|c|}{$\begin{array}{l}\text { Stock-to-Wealth } \\
\text { Ratio }\end{array}$} & \multicolumn{2}{|c|}{$\begin{array}{l}\text { Basis-to-Price } \\
\text { Ratio }\end{array}$} & \multicolumn{2}{|c|}{$\begin{array}{c}\text { Cumulative Capital } \\
\text { Gain Tax-to-Wealth } \\
\text { Ratio }\end{array}$} & $\begin{array}{l}\text { LUL Carry } \\
\text { Over Loss- } \\
\text { to-Wealth }\end{array}$ \\
\hline Percentile & FUL & LUL & FUL & LUL & FUL & LUL & FUL & LUL & Ratio \\
\hline $10 \%$ & 266.0 & 266.0 & $20.2 \%$ & $18.4 \%$ & $5.2 \%$ & $5.3 \%$ & $-1.1 \%$ & $0.0 \%$ & $0.0 \%$ \\
\hline $20 \%$ & 301.3! & 296.1 & $22.2 \%$ & $20.2 \%$ & $9.1 \%$ & $9.1 \%$ & $-0.3 \%$ & $0.0 \%$ & $0.0 \%$ \\
\hline $30 \%$ & 329.1 & 321.2 & $23.3 \%$ & $22.1 \%$ & $13.5 \%$ & $13.6 \%$ & $0.1 \%$ & $0.1 \%$ & $0.0 \%$ \\
\hline $40 \%$ & 355.3 & 346.0 & $25.4 \%$ & $23.6 \%$ & $18.7 \%$ & $18.7 \%$ & $0.3 \%$ & $0.2 \%$ & $0.0 \%$ \\
\hline $50 \%$ & 383.9 & 372.9 & $26.7 \%$ & $26.2 \%$ & $25.0 \%$ & $25.2 \%$ & $0.6 \%$ & $0.5 \%$ & $0.0 \%$ \\
\hline $60 \%$ & 416.2 & 404.8 & $29.7 \%$ & $28.8 \%$ & $33.3 \%$ & $33.5 \%$ & $0.8 \%$ & $0.7 \%$ & $0.0 \%$ \\
\hline $70 \%$ & 457.3 & 445.2 & $30.9 \%$ & $30.8 \%$ & $43.7 \%$ & $44.2 \%$ & $1.1 \%$ & $1.0 \%$ & $0.0 \%$ \\
\hline $80 \%$ & 515.5 & 503.5 & $34.8 \%$ & $34.9 \%$ & $56.8 \%$ & $57.9 \%$ & $1.5 \%$ & $1.4 \%$ & $0.0 \%$ \\
\hline $90 \%$ & 612.7 & 602.5 & $38.9 \%$ & $39.0 \%$ & $76.3 \%$ & $77.7 \%$ & $2.2 \%$ & $2.2 \%$ & $0.0 \%$ \\
\hline Mean & 419.9 & 411.4 & $28.1 \%$ & $27.2 \%$ & $33.3 \%$ & $33.5 \%$ & $0.6 \%$ & $0.8 \%$ & $0.3 \%$ \\
\hline Std.Dev. & 157.2 & 154.6 & $6.4 \%$ & $7.1 \%$ & $27.1 \%$ & $27.3 \%$ & $1.4 \%$ & $1.0 \%$ & $1.8 \%$ \\
\hline \multicolumn{10}{|c|}{ Panel C - Age 80} \\
\hline & \multicolumn{2}{|c|}{ Wealth } & \multicolumn{2}{|c|}{$\begin{array}{c}\text { Stock-to-Wealth } \\
\text { Ratio }\end{array}$} & \multicolumn{2}{|c|}{$\begin{array}{l}\text { Basis-to-Price } \\
\text { Ratio }\end{array}$} & \multicolumn{2}{|c|}{$\begin{array}{c}\text { Cumulative Capital } \\
\text { Gain Tax-to-Wealth } \\
\text { Ratio }\end{array}$} & $\begin{array}{l}\text { LUL Carry } \\
\text { Over Loss- } \\
\text { to-Wealth }\end{array}$ \\
\hline Percentile & FUL & LUL & FUL & LUL & FUL & LUL & FUL & LUL & Ratio \\
\hline $10 \%$ & 485.0 & 481.2 & $21.7 \%$ & $18.8 \%$ & $3.7 \%$ & $3.8 \%$ & $-0.8 \%$ & $0.0 \%$ & $0.0 \%$ \\
\hline $20 \%$ & 567.2 & 550.4 & $23.3 \%$ & $20.8 \%$ & $5.8 \%$ & $5.8 \%$ & $-0.1 \%$ & $0.1 \%$ & $0.0 \%$ \\
\hline $30 \%$ & 636.9 & 614.8 & $25.2 \%$ & $22.7 \%$ & $8.3 \%$ & $8.4 \%$ & $0.2 \%$ & $0.2 \%$ & $0.0 \%$ \\
\hline $40 \%$ & 705.7 & 680.9 & $26.8 \%$ & $24.9 \%$ & $12.4 \%$ & $12.4 \%$ & $0.4 \%$ & $0.3 \%$ & $0.0 \%$ \\
\hline $50 \%$ & 779.5 & 752.4 & $29.6 \%$ & $27.3 \%$ & $18.1 \%$ & $18.0 \%$ & $0.6 \%$ & $0.5 \%$ & $0.0 \%$ \\
\hline $60 \%$ & 869.0 & 838.6 & $32.3 \%$ & $30.6 \%$ & $26.2 \%$ & $25.5 \%$ & $0.8 \%$ & $0.8 \%$ & $0.0 \%$ \\
\hline $70 \%$ & 983.2 & 953.2 & $35.2 \%$ & $34.6 \%$ & $37.0 \%$ & $35.7 \%$ & $1.1 \%$ & $1.1 \%$ & $0.0 \%$ \\
\hline $80 \%$ & 1149.8 & 1120.7 & $39.3 \%$ & $38.5 \%$ & $50.9 \%$ & $49.9 \%$ & $1.6 \%$ & $1.5 \%$ & $0.0 \%$ \\
\hline $90 \%$ & 1454.6 & 1417.5 & $44.7 \%$ & $44.3 \%$ & $73.0 \%$ & $71.0 \%$ & $2.2 \%$ & $2.2 \%$ & $0.0 \%$ \\
\hline Mean & 898.7! & 876.7 & $31.2 \%$ & $29.5 \%$ & $28.6 \%$ & $28.0 \%$ & $0.6 \%$ & $0.9 \%$ & $0.2 \%$ \\
\hline Std.Dev. & 457.8i & 454.1 & $8.5 \%$ & $9.3 \%$ & $26.9 \%$ & $26.4 \%$ & $1.3 \%$ & $0.9 \%$ & $1.4 \%$ \\
\hline
\end{tabular}


Table 7: Capital Gain Tax 30\% Case Simulations. This table presents simulation results for portfolio characteristics under the FUL and the LUL cases at ages 40, 60, and 80 over 50, 000 paths. The investor starts at age 20 with no embedded capital gains and zero carry-over loss (LUL cases). The parameters used are the Capital Gain Tax 30\% Case parameters summarized in Section 2.4.

Panel A - Age 40

\begin{tabular}{|c|c|c|c|c|c|c|c|c|c|}
\hline \multirow[b]{2}{*}{ Percentile } & \multicolumn{2}{|c|}{ Wealth } & \multicolumn{2}{|c|}{$\begin{array}{c}\text { Stock-to-Wealth } \\
\text { Ratio }\end{array}$} & \multicolumn{2}{|c|}{$\begin{array}{c}\text { Basis-to-Price } \\
\text { Ratio }\end{array}$} & \multicolumn{2}{|c|}{$\begin{array}{c}\text { Cumulative Capital } \\
\text { Gain Tax-to-Wealth } \\
\text { Ratio }\end{array}$} & \multirow{2}{*}{$\begin{array}{l}\text { LUL Carry } \\
\text { Over Loss- } \\
\text { to-Wealth } \\
\text { Ratio }\end{array}$} \\
\hline & FUL & LUL & FUL & LUL & FUL & LUL & FUL & LUL & \\
\hline $10 \%$ & 152.7 & 155.2 & $21.7 \%$ & $17.2 \%$ & $15.0 \%$ & $15.7 \%$ & $-3.8 \%$ & $0.0 \%$ & $0.0 \%$ \\
\hline $20 \%$ & 164.4 & 165.7 & $23.2 \%$ & $19.0 \%$ & $21.0 \%$ & $21.7 \%$ & $-2.4 \%$ & $0.0 \%$ & $0.0 \%$ \\
\hline $30 \%$ & 174.9 & 174.8 & $25.3 \%$ & $20.3 \%$ & $26.2 \%$ & $26.5 \%$ & $-1.4 \%$ & $0.0 \%$ & $0.0 \%$ \\
\hline $40 \%$ & 185.9 & 183.2 & $28.0 \%$ & $22.4 \%$ & $35.0 \%$ & $35.1 \%$ & $-0.9 \%$ & $0.0 \%$ & $0.0 \%$ \\
\hline $50 \%$ & 194.5 & 189.1 & $29.7 \%$ & $23.6 \%$ & $39.5 \%$ & $39.9 \%$ & $-0.4 \%$ & $0.0 \%$ & $0.0 \%$ \\
\hline $60 \%$ & 208.4 & 199.9 & $33.0 \%$ & $26.4 \%$ & $49.2 \%$ & $50.2 \%$ & $0.0 \%$ & $0.0 \%$ & $0.0 \%$ \\
\hline $70 \%$ & 223.0 & 210.4 & $35.6 \%$ & $29.9 \%$ & $57.2 \%$ & $58.3 \%$ & $0.3 \%$ & $0.0 \%$ & $0.0 \%$ \\
\hline $80 \%$ & 246.0 & 226.8 & $39.9 \%$ & $34.4 \%$ & $70.6 \%$ & $74.1 \%$ & $0.7 \%$ & $0.0 \%$ & $0.0 \%$ \\
\hline $90 \%$ & 283.4 & 260.6 & $44.9 \%$ & $40.3 \%$ & $86.6 \%$ & $89.2 \%$ & $1.8 \%$ & $0.0 \%$ & $0.0 \%$ \\
\hline $\begin{array}{l}\text { Mean } \\
\text { Std.Dev. }\end{array}$ & $\begin{array}{r}210.5 \\
59.1\end{array}$ & $\begin{array}{r}201.8 \\
50.0\end{array}$ & $\begin{array}{r}31.5 \% \\
8.2 \%\end{array}$ & $\begin{array}{r}26.6 \% \\
8.9 \%\end{array}$ & $\begin{array}{l}45.6 \% \\
26.1 \%\end{array}$ & $\begin{array}{l}46.4 \% \\
26.6 \%\end{array}$ & $\begin{array}{r}-0.8 \% \\
2.4 \%\end{array}$ & $\begin{array}{l}0.1 \% \\
0.6 \%\end{array}$ & $\begin{array}{l}0.1 \% \\
0.6 \%\end{array}$ \\
\hline \multicolumn{10}{|c|}{ Panel B - Age 60} \\
\hline & \multicolumn{2}{|c|}{ Wealth } & \multicolumn{2}{|c|}{$\begin{array}{c}\text { Stock-to-Wealth } \\
\text { Ratio }\end{array}$} & \multicolumn{2}{|c|}{$\begin{array}{l}\text { Basis-to-Price } \\
\text { Ratio }\end{array}$} & \multicolumn{2}{|c|}{$\begin{array}{c}\text { Cumulative Capital } \\
\text { Gain Tax-to-Wealth } \\
\text { Ratio }\end{array}$} & $\begin{array}{l}\text { LUL Carry } \\
\text { Over Loss- } \\
\text { to-Wealth }\end{array}$ \\
\hline Percentile & FUL & LUL & FUL & LUL & FUL & LUL & FUL & LUL & Ratio \\
\hline $10 \%$ & 265.8 & 267.9 & $22.7 \%$ & $18.6 \%$ & $5.3 \%$ & $5.3 \%$ & $-3.0 \%$ & $0.0 \%$ & $0.0 \%$ \\
\hline $20 \%$ & 298.7 & 296.2 & $25.0 \%$ & $20.7 \%$ & $8.7 \%$ & $8.8 \%$ & $-1.6 \%$ & $0.0 \%$ & $0.0 \%$ \\
\hline $30 \%$ & 327.0 & 319.2 & $27.2 \%$ & $22.8 \%$ & $12.1 \%$ & $12.4 \%$ & $-0.8 \%$ & $0.0 \%$ & $0.0 \%$ \\
\hline $40 \%$ & 354.9 & 341.9 & $30.1 \%$ & $25.1 \%$ & $16.3 \%$ & $16.8 \%$ & $-0.3 \%$ & $0.0 \%$ & $0.0 \%$ \\
\hline $50 \%$ & 388.4 & 366.9 & $33.3 \%$ & $28.3 \%$ & $21.4 \%$ & $22.8 \%$ & $0.0 \%$ & $0.0 \%$ & $0.0 \%$ \\
\hline $60 \%$ & 427.3 & 398.2 & $36.3 \%$ & $31.7 \%$ & $28.9 \%$ & $31.4 \%$ & $0.3 \%$ & $0.0 \%$ & $0.0 \%$ \\
\hline $70 \%$ & 480.3 & 441.0 & $40.1 \%$ & $36.4 \%$ & $37.9 \%$ & $41.2 \%$ & $0.8 \%$ & $0.0 \%$ & $0.0 \%$ \\
\hline $80 \%$ & 559.3 & 509.7 & $44.9 \%$ & $41.9 \%$ & $52.2 \%$ & $56.0 \%$ & $1.7 \%$ & $0.3 \%$ & $0.3 \%$ \\
\hline $90 \%$ & 711.8 & 648.5 & $50.5 \%$ & $49.3 \%$ & $74.1 \%$ & $76.1 \%$ & $3.3 \%$ & $2.2 \%$ & $2.2 \%$ \\
\hline Mean & 450.9 & 428.5 & $34.9 \%$ & $31.2 \%$ & $30.6 \%$ & $32.1 \%$ & $0.0 \%$ & $0.6 \%$ & $0.6 \%$ \\
\hline Std.Dev. & 218.5 & 552.1 & $10.4 \%$ & $11.1 \%$ & $26.1 \%$ & $27.0 \%$ & $2.7 \%$ & $1.4 \%$ & $1.4 \%$ \\
\hline \multicolumn{10}{|c|}{ Panel C - Age 80} \\
\hline & \multicolumn{2}{|c|}{ Wealth } & \multicolumn{2}{|c|}{$\begin{array}{c}\text { Stock-to-Wealth } \\
\text { Ratio }\end{array}$} & \multicolumn{2}{|c|}{$\begin{array}{c}\text { Basis-to-Price } \\
\text { Ratio }\end{array}$} & \multicolumn{2}{|c|}{$\begin{array}{c}\text { Cumulative Capital } \\
\text { Gain Tax-to-Wealth } \\
\text { Ratio }\end{array}$} & $\begin{array}{l}\text { LUL Carry } \\
\text { Over Loss- } \\
\text { to-Wealth }\end{array}$ \\
\hline Percentile & FUL & LUL & FUL & LUL & FUL & LUL & FUL & LUL & Ratio \\
\hline $10 \%$ & 480.6 & 479.9 & $24.1 \%$ & $19.3 \%$ & $3.0 \%$ & $3.1 \%$ & $-2.4 \%$ & $0.0 \%$ & $0.0 \%$ \\
\hline $20 \%$ & 563.1 & 544.4 & $27.6 \%$ & $21.7 \%$ & $4.8 \%$ & $5.0 \%$ & $-1.1 \%$ & $0.0 \%$ & $0.0 \%$ \\
\hline $30 \%$ & 636.7 & 602.1 & $29.9 \%$ & $23.8 \%$ & $6.8 \%$ & $7.2 \%$ & $-0.5 \%$ & $0.0 \%$ & $0.0 \%$ \\
\hline $40 \%$ & 712.1 & 663.2 & $33.1 \%$ & $27.1 \%$ & $9.7 \%$ & $10.4 \%$ & $-0.2 \%$ & $0.0 \%$ & $0.0 \%$ \\
\hline $50 \%$ & 797.7 & 731.2 & $36.5 \%$ & $30.7 \%$ & $13.8 \%$ & $14.9 \%$ & $0.0 \%$ & $0.0 \%$ & $0.0 \%$ \\
\hline $60 \%$ & 909.2 & 819.3 & $40.3 \%$ & $35.1 \%$ & $20.3 \%$ & $21.6 \%$ & $0.2 \%$ & $0.0 \%$ & $0.0 \%$ \\
\hline $70 \%$ & 1062.0 & 949.5 & $45.2 \%$ & $40.2 \%$ & $29.5 \%$ & $31.5 \%$ & $0.6 \%$ & $0.1 \%$ & $0.0 \%$ \\
\hline $80 \%$ & 1307.4 & 1159.1 & $51.1 \%$ & $46.7 \%$ & $44.1 \%$ & $45.8 \%$ & $1.3 \%$ & $0.6 \%$ & $0.0 \%$ \\
\hline $90 \%$ & 1821.2 & 1610.1 & $58.8 \%$ & $55.2 \%$ & $66.4 \%$ & $67.2 \%$ & $2.6 \%$ & $2.0 \%$ & $0.0 \%$ \\
\hline Mean & 1027.4 & 951.8 & $39.2 \%$ & $34.2 \%$ & $24.8 \%$ & $25.7 \%$ & $0.0 \%$ & $0.5 \%$ & $0.2 \%$ \\
\hline Std.Dev. & 751.5 & 1314.0 & $13.0 \%$ & $13.7 \%$ & $25.7 \%$ & $25.9 \%$ & $2.3 \%$ & $1.2 \%$ & $1.4 \%$ \\
\hline
\end{tabular}


Table 8: Capital Gain Tax 50\% Case, Lower Risk Aversion Case, and No Tax Forgiveness at Death Case Simulations. This table presents simulation results for portfolio characteristics under the FUL and the LUL cases at age 80 over 50,000 paths. The investor starts at age 20 with no embedded capital gains and zero carry-over loss (LUL cases). The parameters used are the Capital Gain Tax 50\% Case, the Lower Risk Aversion Case, and the No Tax Forgiveness at Death Case parameters summarized in Section 2.4.

Panel A - Capital Gain Tax Rate 50\% Case - Age 80

\begin{tabular}{|c|c|c|c|c|c|c|c|c|c|}
\hline \multirow[b]{2}{*}{ Percentile } & \multicolumn{2}{|c|}{ Wealth } & \multicolumn{2}{|c|}{$\begin{array}{c}\text { Stock-to-Wealth } \\
\text { Ratio }\end{array}$} & \multicolumn{2}{|c|}{$\begin{array}{c}\text { Basis-to-Price } \\
\text { Ratio }\end{array}$} & \multicolumn{2}{|c|}{$\begin{array}{c}\text { Cumulative Capital } \\
\text { Gain Tax-to-Wealth } \\
\text { Ratio }\end{array}$} & \multirow{2}{*}{$\begin{array}{l}\text { LUL Carry } \\
\text { Over Loss- } \\
\text { to-Wealth } \\
\text { Ratio }\end{array}$} \\
\hline & FUL & LUL & FUL & LUL & FUL & LUL & FUL & LUL & \\
\hline $10 \%$ & $481.3 i$ & 476.2 & $28.4 \%$ & $20.7 \%$ & $2.0 \%$ & $1.9 \%$ & $-4.9 \%$ & $0.0 \%$ & $0.0 \%$ \\
\hline $20 \%$ & 575.4 & 549.8 & $33.7 \%$ & $23.3 \%$ & $3.6 \%$ & $3.6 \%$ & $-2.4 \%$ & $0.0 \%$ & $0.0 \%$ \\
\hline $30 \%$ & 657.8 & 622.8 & $38.2 \%$ & $26.6 \%$ & $5.5 \%$ & $5.5 \%$ & $-1.3 \%$ & $0.0 \%$ & $0.0 \%$ \\
\hline $40 \%$ & 745.4 & 693.1 & $40.8 \%$ & $30.0 \%$ & $8.0 \%$ & $8.0 \%$ & $-0.8 \%$ & $0.0 \%$ & $0.0 \%$ \\
\hline $50 \%$ & 850.4 & 765.6 & $45.0 \%$ & $34.0 \%$ & $11.5 \%$ & $11.6 \%$ & $-0.5 \%$ & $0.0 \%$ & $0.0 \%$ \\
\hline $60 \%$ & 996.0 & 857.7 & $49.4 \%$ & $38.6 \%$ & $16.7 \%$ & $16.8 \%$ & $-0.2 \%$ & $0.0 \%$ & $0.0 \%$ \\
\hline $70 \%$ & 1206.8 & 987.9 & $54.7 \%$ & $44.2 \%$ & $25.0 \%$ & $24.1 \%$ & $-0.1 \%$ & $0.0 \%$ & $0.0 \%$ \\
\hline $80 \%$ & 1582.3 & 1207.2 & $61.2 \%$ & $51.2 \%$ & $39.2 \%$ & $36.4 \%$ & $0.0 \%$ & $0.0 \%$ & $0.0 \%$ \\
\hline $90 \%$ & 2490.2 & 1706.2 & $69.5 \%$ & $61.4 \%$ & $62.6 \%$ & $59.5 \%$ & $0.1 \%$ & $0.1 \%$ & $0.0 \%$ \\
\hline Mean & 1330.7 & 1029.6 & $47.3 \%$ & $37.7 \%$ & $22.3 \%$ & $21.6 \%$ & $-1.7 \%$ & $0.0 \%$ & $0.2 \%$ \\
\hline Std.Dev. & 1761.1! & 1086.3 & $15.2 \%$ & $15.6 \%$ & $25.0 \%$ & $24.3 \%$ & $3.5 \%$ & $0.1 \%$ & $1.4 \%$ \\
\hline \multicolumn{10}{|c|}{ Panel B - Lower Risk Aversion Case - Age 80} \\
\hline & \multicolumn{2}{|c|}{ Wealth } & \multicolumn{2}{|c|}{$\begin{array}{l}\text { Stock-to-Wealth } \\
\text { Ratio }\end{array}$} & \multicolumn{2}{|c|}{$\begin{array}{c}\text { Basis-to-Price } \\
\text { Ratio }\end{array}$} & \multicolumn{2}{|c|}{$\begin{array}{c}\text { Cumulative Capital } \\
\text { Gain Tax-to-Wealth } \\
\text { Ratio }\end{array}$} & \multirow{2}{*}{$\begin{array}{c}\text { LUL Carry } \\
\text { Over Loss- } \\
\text { to-Wealth } \\
\text { Ratio }\end{array}$} \\
\hline Percentile & FUL & LUL & FUL & LUL & FUL & LUL & FUL & LUL & \\
\hline $10 \%$ & $420.5 i$ & 422.4 & $32.0 \%$ & $29.5 \%$ & $3.1 \%$ & $3.1 \%$ & $-1.4 \%$ & $0.0 \%$ & $0.0 \%$ \\
\hline $20 \%$ & 531.4 & 515.0 & $35.6 \%$ & $32.3 \%$ & $5.3 \%$ & $5.3 \%$ & $-0.4 \%$ & $0.0 \%$ & $0.0 \%$ \\
\hline $30 \%$ & 631.5 & 603.8 & $38.0 \%$ & $34.4 \%$ & $7.8 \%$ & $7.8 \%$ & $0.0 \%$ & $0.0 \%$ & $0.0 \%$ \\
\hline $40 \%$ & 735.3 & 698.6 & $40.5 \%$ & $36.8 \%$ & $11.3 \%$ & $11.1 \%$ & $0.2 \%$ & $0.2 \%$ & $0.0 \%$ \\
\hline $50 \%$ & 849.6 & 804.3 & $44.3 \%$ & $40.3 \%$ & $16.6 \%$ & $16.1 \%$ & $0.5 \%$ & $0.4 \%$ & $0.0 \%$ \\
\hline $60 \%$ & 994.2 & 938.2 & $46.3 \%$ & $44.4 \%$ & $24.4 \%$ & $23.4 \%$ & $0.7 \%$ & $0.6 \%$ & $0.0 \%$ \\
\hline $70 \%$ & 1188.1 & 1128.0 & $50.2 \%$ & $49.2 \%$ & $34.5 \%$ & $33.2 \%$ & $1.0 \%$ & $0.9 \%$ & $0.0 \%$ \\
\hline $80 \%$ & 1486.6 & 1420.9 & $54.8 \%$ & $54.0 \%$ & $48.2 \%$ & $47.3 \%$ & $1.4 \%$ & $1.4 \%$ & $0.0 \%$ \\
\hline $90 \%$ & 2074.6 & 1977.4 & $60.5 \%$ & $60.0 \%$ & $69.9 \%$ & $68.7 \%$ & $2.1 \%$ & $2.1 \%$ & $0.0 \%$ \\
\hline Mean & 1112.0 & 1069.8 & $45.1 \%$ & $42.7 \%$ & $27.0 \%$ & $26.5 \%$ & $0.3 \%$ & $0.7 \%$ & $0.3 \%$ \\
\hline Std.Dev. & 908.1 & 892.3 & $10.1 \%$ & $11.0 \%$ & $26.3 \%$ & $26.1 \%$ & $1.7 \%$ & $0.9 \%$ & $2.2 \%$ \\
\hline \multicolumn{10}{|c|}{ Panel C - No Tax Forgiveness at Death Case - Age 80} \\
\hline & \multicolumn{2}{|c|}{ Wealth } & \multicolumn{2}{|c|}{$\begin{array}{c}\text { Stock-to-Wealth } \\
\text { Ratio }\end{array}$} & \multicolumn{2}{|c|}{$\begin{array}{c}\text { Basis-to-Price } \\
\text { Ratio }\end{array}$} & \multicolumn{2}{|c|}{$\begin{array}{c}\text { Cumulative Capital } \\
\text { Gain Tax-to-Wealth } \\
\text { Ratio }\end{array}$} & \multirow{2}{*}{$\begin{array}{c}\text { LUL Carry } \\
\text { Over Loss- } \\
\text { to-Wealth } \\
\text { Ratio }\end{array}$} \\
\hline Percentile & FUL & LUL & FUL & LUL & FUL & LUL & FUL & LUL & \\
\hline $10 \%$ & $493.1 \mathrm{i}$ & 486.7 & $21.0 \%$ & $20.2 \%$ & $3.3 \%$ & $3.2 \%$ & $-0.3 \%$ & $0.2 \%$ & $0.0 \%$ \\
\hline $20 \%$ & 574.8 & 560.3 & $22.4 \%$ & $20.8 \%$ & $6.6 \%$ & $6.4 \%$ & $0.4 \%$ & $0.5 \%$ & $0.0 \%$ \\
\hline $30 \%$ & 642.6 & 625.4 & $23.4 \%$ & $22.4 \%$ & $11.1 \%$ & $10.6 \%$ & $0.7 \%$ & $0.7 \%$ & $0.0 \%$ \\
\hline $40 \%$ & 708.1 & 690.6 & $24.4 \%$ & $23.4 \%$ & $17.3 \%$ & $16.3 \%$ & $1.0 \%$ & $1.0 \%$ & $0.0 \%$ \\
\hline $50 \%$ & 778.2 & 758.2 & $25.3 \%$ & $25.0 \%$ & $24.9 \%$ & $23.5 \%$ & $1.3 \%$ & $1.3 \%$ & $0.0 \%$ \\
\hline $60 \%$ & 860.7 & 836.7 & $26.5 \%$ & $26.3 \%$ & $33.8 \%$ & $32.3 \%$ & $1.7 \%$ & $1.6 \%$ & $0.0 \%$ \\
\hline $70 \%$ & 961.3 & 937.3 & $28.1 \%$ & $27.8 \%$ & $45.3 \%$ & $43.2 \%$ & $2.0 \%$ & $2.0 \%$ & $0.0 \%$ \\
\hline $80 \%$ & 1104.1 & 1080.0 & $29.3 \%$ & $29.5 \%$ & $59.5 \%$ & $57.1 \%$ & $2.5 \%$ & $2.4 \%$ & $0.0 \%$ \\
\hline $90 \%$ & 1343.9 & 1309.5 & $30.9 \%$ & $31.0 \%$ & $79.5 \%$ & $76.1 \%$ & $3.1 \%$ & $3.1 \%$ & $0.0 \%$ \\
\hline Mean & 866.5 & 847.2 & $25.8 \%$ & $25.3 \%$ & $33.1 \%$ & $31.9 \%$ & $1.3 \%$ & $1.5 \%$ & $0.2 \%$ \\
\hline Std.Dev. & 379.6 & 373.7 & $3.6 \%$ & $4.0 \%$ & $28.4 \%$ & $27.8 \%$ & $1.5 \%$ & $1.1 \%$ & $1.5 \%$ \\
\hline
\end{tabular}




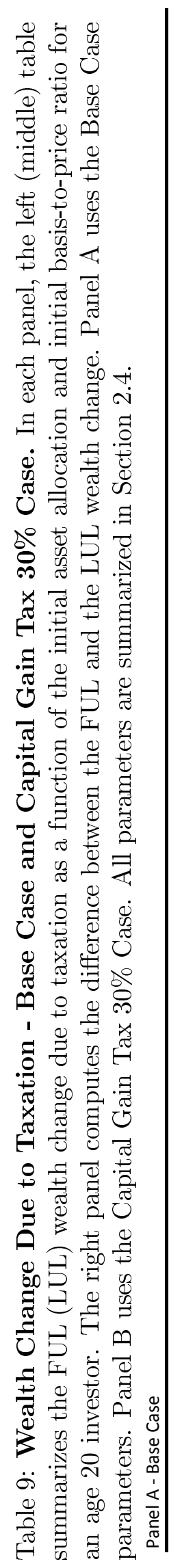

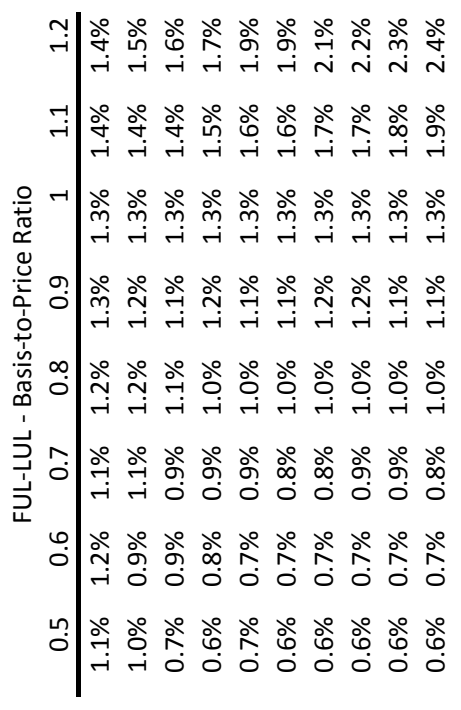

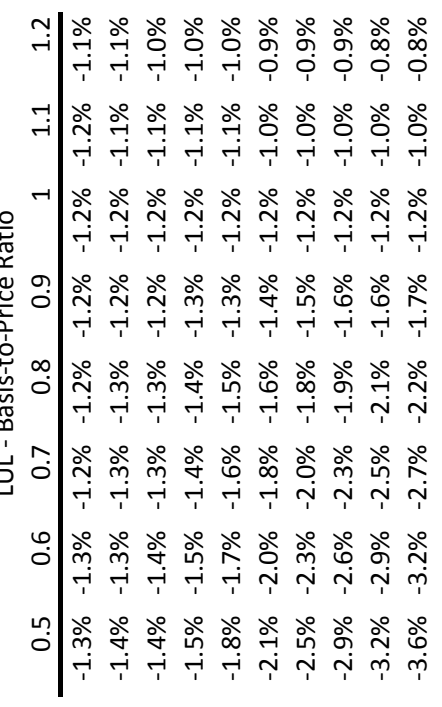

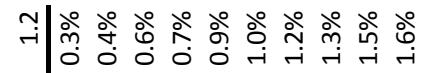

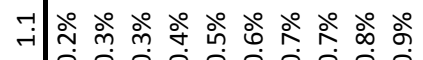

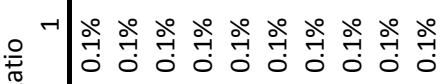
\% 产

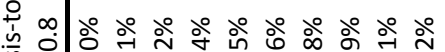
苋

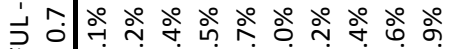
(1)

๑. ㅇ ㅇํำ ㅇํㅇ ㅇ

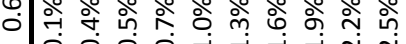
ก)

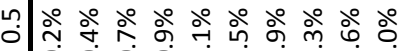
i

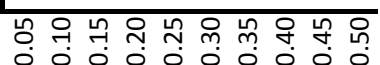
uo!m!sod yวots |e!?!u|

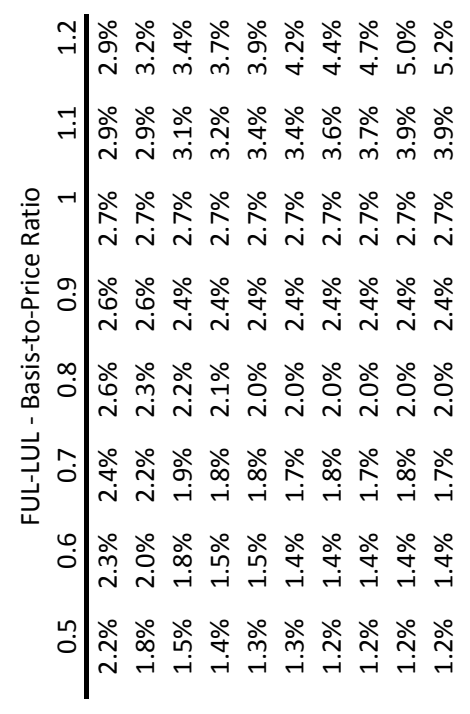

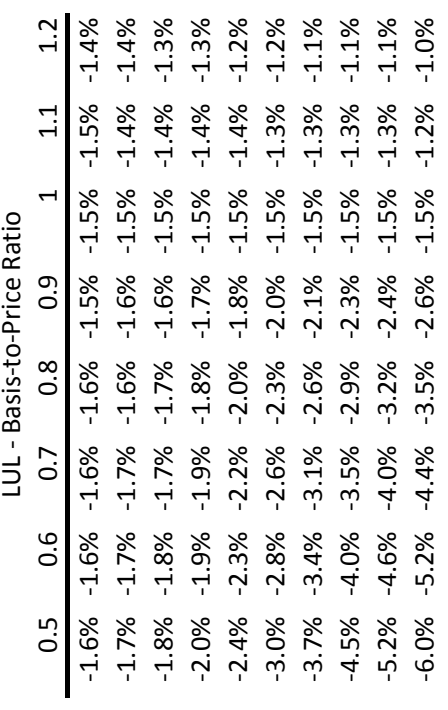

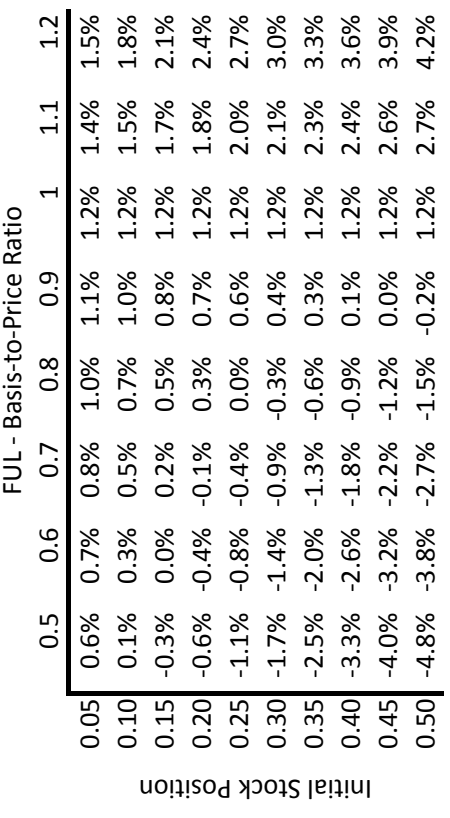




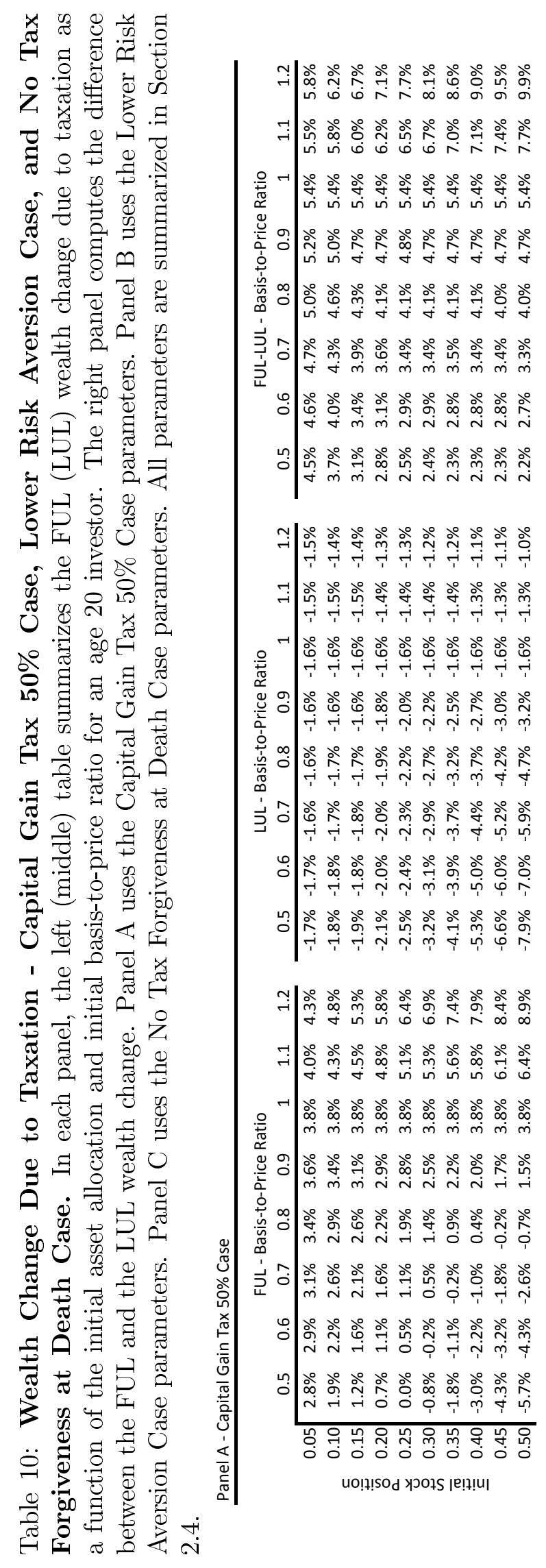

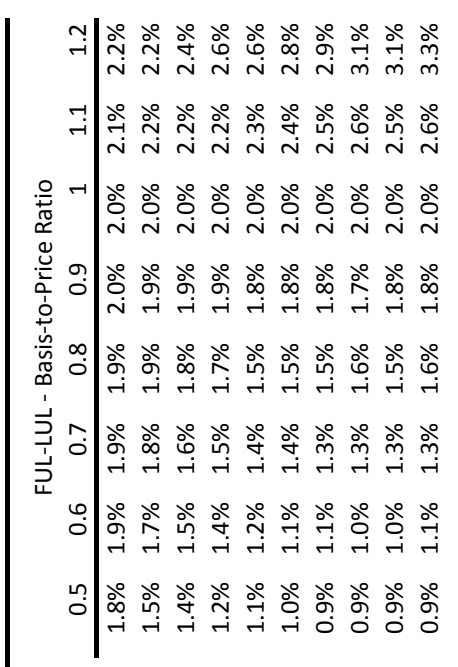

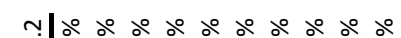
ᄀ| ت -1

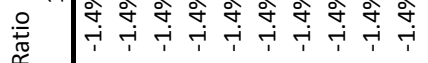

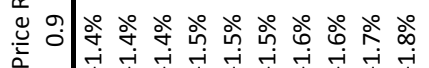
高 Ұं

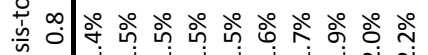

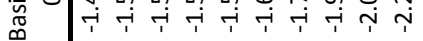

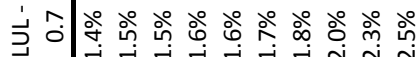

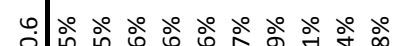
i † † † † นุ.

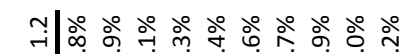
न|l ○

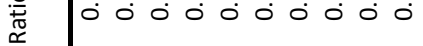

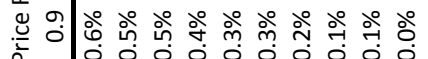
㻤

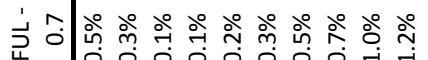

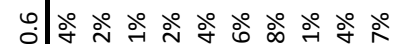
o o i o i i i i i T

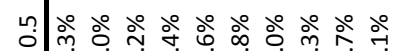

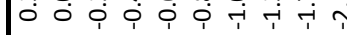

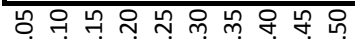
○ 000000000

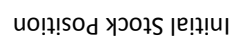

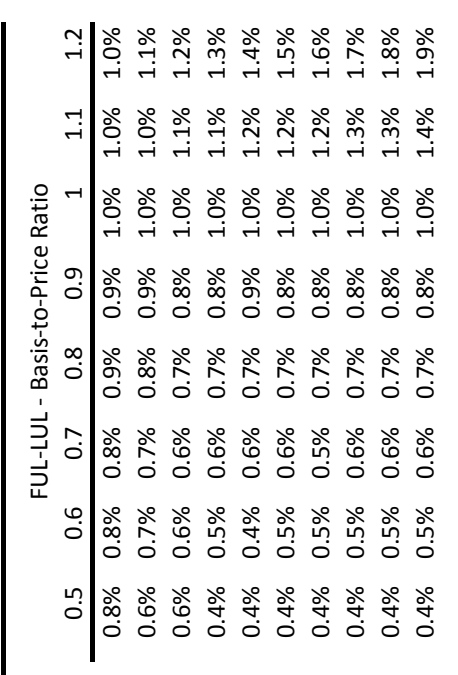

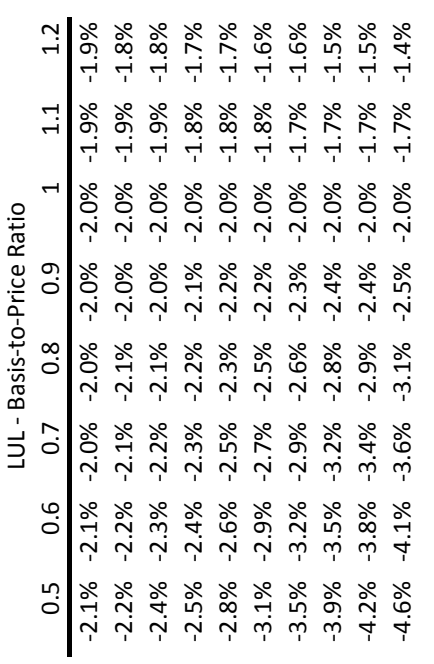

تิ न

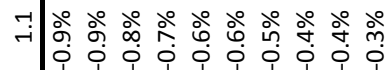
○ -

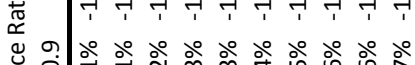

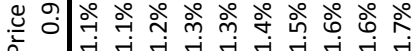
㝘

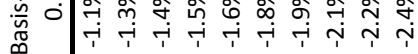

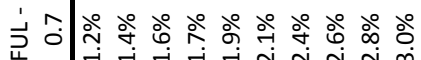
0.00

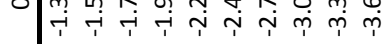

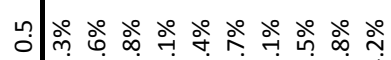
in

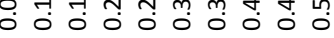

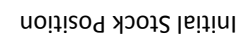

